Article

\section{2}

\title{
Ataxin-2 Binds Alpha-Actinin-1
}

\author{
Florian Eich ${ }^{1}$, David F. Nonis ${ }^{1}$, Nesli-Ece Sen ${ }^{1}$, Joachim Nowock ${ }^{1}$, Georg Auburger 1,* \\ 1 Exp. Neurology, Building 89, Medical Faculty, Goethe University, Theodor Stern Kai 7, 60590 Frankfurt \\ am Main, Germany; Florian.Eich@olympus-europa.com (F.E.); davidnonis@yahoo.com.ar (D.F.N.); \\ nesliecesen@gmail.com (N.-E.S.); nowock@gmx.de (J.N.); auburger@em.uni-frankfurt.de (G.A.) \\ * Correspondence: auburger@em.uni-frankfurt.de; Tel.: +49-69-6301-7428
}

\begin{abstract}
Ataxin-2 (human gene symbol ATXN2, protein ATXN2) is the disease protein of Spinocerebellar Ataxia type 2 (SCA2). The large expansions of a polyglutamine (polyQ) stretch above a threshold of $\sim 33$ glutamines cause the multi-system nervous atrophy SCA2, while intermediate expansions of 29-32 glutamines contribute to the risk of the motor neuron diseases Amyotrophic Lateral Sclerosis (ALS) and Fronto-Temporal Lobar Dementia (FTLD). To elucidate the cellular function of ATXN2, we further characterized its direct interaction with alpha-Actinin-1 (symbol ACTN1), which had been observed in high-throughput yeast-two-hybrid surveys. An endogenous complex of ATXN2 and ACTN1 proteins was detected by co-immunoprecipitation. In vitro GST-tag pull-down experiments showed that the Calponin-Homology-domain at the $\mathrm{N}$-terminus of ACTN1 binds to the N-terminus of ATXN2. Although an impact of the polyQ expansion on the interaction was not evident in pull-down experiments, a recent characterization of aged Atxn2-CAG100-KnockIn mice provides evidence. Both proteins associated in the cytosol and at the plasma membrane, as determined by sedimentation experiments in mouse brain, and by immunofluorescence microscopy of a transfected monkey cell line and of rat primary hippocampal neurons. In view of the roles of ACTN1 for spine plasticity and postsynaptic receptor control via reassembly of cortical actin, our data help to explain the impaired dendrite maintenance in SCA2.
\end{abstract}

Keywords: olivo-ponto-cerebellar atrophy (OPCA); Purkinje cells; Calcium/calmodulin dependent protein kinase II (CAMK2); Plastin (Fimbrin); Hirano bodies; Huntington's disease.

\section{Introduction}

Spinocerebellar ataxia type 2 (SCA2) is an autosomal-dominant neurodegenerative disorder which is caused by the expansion of a (CAG)-triplet-repeat encoding a polyglutamine (polyQ) domain [1-3]. Upon large expansions beyond the critical threshold ( 33Q) within the Ataxin-2 protein (human gene symbol ATXN2, protein symbol ATXN2), a multi-system atrophy in the nervous system ensues, which was previously described by clinical neurologists as cerebellar ataxia with slowed saccadic eye movements [4-9], by neuropathologists as olivo-ponto-cerebellar atrophy [10-26], and was defined by genetic analyses as SCA2 [27-34]. Upon intermediate expansions between $29 \mathrm{Q}$ and $32 \mathrm{Q}$, the risk to be affected by tauopathies such as the motor neuron diseases Amyotrophic Lateral Sclerosis (ALS) and Fronto-Temporal Lobar Dementia (FTLD), or the Parkinson-plus variant PSP (Progressive Supranuclear Palsy) is increased [35-47]. Similar polyQ expansion mutations were identified in an increasing number of different genes to underlie neurodegenerative processes, and the resulting diseases were named 'polyglutamine diseases'. So far five other ataxias (SCA1, SCA3, SCA6, SCA7, SCA17), Huntington's disease (HD), spinobulbar muscular atrophy (SMA), and dentatorubro-pallidoluysian atrophy (DRPLA) [48, 49] have been reported. There are intense investigations to elucidate the mechanisms how expanded polyQ domains lead to neural dysfunction and finally cell loss in the nervous system [50-56].

When polyQ domains are expanded to pathogenic length, they show an increased propensity to change the protein conformation. The turnover of such proteins is altered and insoluble aggregates 
are formed, which show an amyloid morphology [57, 58]. In post-mitotic neurons, this cumulative aggregation process may eventually fill the affected subcellular compartment and trigger the expulsion of aggregates from the cell via exosomes [59], as well as their internalization by adjacent microglia [60, 61]. The role of such aggregates (inclusion bodies) is controversially discussed. On the one hand, they mediate a toxic gain-of-function of the disease protein, sequestrate essential factors among its physiological interactome into the aggregation process [62], and represent a burden for the protein degradation systems via the ubiquitin-proteasome pathway as well as the autophagy pathway [63]; on the other hand, they were suggested to play also a protective role $[64,65]$.

Each of the nine polyQ diseases triggers a specific neurodegeneration pattern in the nervous system [66], so the affected neuron populations vary in dependence on the disease protein structure, expression profile, subcellular localization and interacting molecules. In the case of ATXN2, it was demonstrated that its cytosolic interactor protein PABPC1 [poly(A)-binding protein cytoplasmic 1] as well as nuclear RNA-processing factors are recruited into the inclusion bodies, but this sequestration process also extends to the calcium-dynamics endoplasmic reticulum factor ITPR 1 and the mitochondrial autophagy effector Parkin $[50,51,53,54,61,67]$. The spinocerebellar degeneration pattern of SCA2 is easily explained by the preferential expression of ATXN2 in the cerebellum together with specific brainstem and spinal cord neurons, e.g. cerebellar Purkinje cells and motor neurons [68]. However, ATXN2 is ubiquitously expressed and plays a major role also in female sexual organs, blood vessels and lung (https://gtexportal.org/home/gene/ATXN2). The subcellular distribution of ATXN2 was shown to be mainly associated with the rough endoplasmic reticulum [69-71], but some ATXN2 is also present at the plasma membrane [72, 73]. During periods of cellular damage, ATXN2 re-localizes to cytosolic stress granules where RNA quality control and triage take place $[74,75]$. Indeed, human ATXN2 was demonstrated to bind mRNAs directly, with preference at their 3'-untranslated region [76, 77]. ATXN2 is phylogenetically conserved in all eukaryotic organisms [78]. For its orthologue in Drosophila melanogaster it was shown that Ataxin-2 physically assembles with ribosomes [76], but another effect of D. melanogaster Ataxin-2 on actin filament formation was never understood in modular detail, or reproduced in other organisms so far [79]. The known direct protein interactors for ATXN2 either confirm the role at the ribosome, like poly(A)-binding cytoplasmic protein 1 (gene symbol PABPC1) [80], ATXN2 binding protein 1 (A2BP1, aka Fox-1-Like RNA-Binding Protein 1, gene symbol RBFOX1) [81], and the RNA helicase DDX6 [74]. The protein interactors of ATXN2 also support an additional function related to endocytosis, in view of its direct association with Endophilin-A (gene symbols SH3GL2, SH3GL3) and a perhaps indirect association with Fimbrins (aka T-/L-Plastin, gene symbols PLS3, LCP1) [72, 82]. Interestingly, the interaction with Endophilin-A is in common between two polyQ disease proteins, namely ATXN2 and Huntingtin, and both non-expanded polyQ proteins become toxic in cells with deletion of the filopodia-enriched Fimbrin [82].

Specific protein sequence motifs within ATXN2 have been identified to be responsible for these interactions. The direct binding to RNAs is mediated by Lsm and LsmAD domains encoded by exons 3-8. Its indirect binding to mRNAs via direct binding to the poly(A)-tail associated PABPC1 is mediated by a Pam2 motif encoded by exon 16 [83]. The aggregation-prone polyQ domain is encoded in exon 1, but is not conserved even in mice. The exon 1 and the alternatively spliced exon 10 encode two proline-rich domain (PRD) of type II, which mediate the association with SH3 motifs within endocytosis factors like SH3GL2, SRC and GRB2 [72, 73]. With exception of the polyQ domain, all these motifs are conserved throughout all eukaryotic organisms, while varying in order [78].

In a large protein-interaction screen of proteins involved in the degeneration of cerebellar Purkinje neurons (Suppl. Table S3 in [84]), alpha-Actinin-1 (protein symbol ACTN1) was reported to directly associate with ATXN2, similar to several other protein fragments from A2BP1, ACTN2, ATXN1, BAT3, CHGB, FLJ35171, GFI1B, IDH3B, KIAA1279, NCOA4, SH3GL2, SH3GL3, TDRD7, ZNRD1 (Suppl. Tables S3/S4 in [84]). In this published survey, a stringent yeast-two-hybrid assay was employed to assess 23 human cDNAs encoding proteins directly involved in ataxias, including 
ATXN2 and its truncation fragments, regarding their interactions with the human ORFeome1.1 [85] and an adult brain library. We focused additional validation work on ACTN1.

This protein occurs ubiquitously in many cell types, while its three homologs ACTN2-4 vary in distribution, two of them representing muscle-selective isoforms. All alpha-actinins form an antiparallel homo-dimer where each end makes contact with actin, while the rod-shaped central region regulates the geometry between actin filaments, an interaction that is diminished and abolished upon calcium elevation [86]. They promote actin turnover, prevent the formation of actin stress-fibers and of rigid adhesions [87, 88]. Alpha-actinins thus establish the symmetric architecture and mobility of the actin-network, integrating the mechanical forces to carry out membrane movements, in adaptation to extracellular cues [89-92]. Beyond binding to actin, they associate with cytoplasmic domains of transmembrane proteins, connecting receptors and ion channels with submembrane platform proteins, such as the postsynaptic integrator PSD-95 [93]. In a signalling function, they were reported to associate with nuclear hormone receptors and potentiate their basal transcription activity [94]. They thus serve as scaffold in the connection of perception signals to the cytoskeleton [95], mediate filopodia movement [96-98], and are important for the rearrangement of cortical actin to open space for vesicle fusion/fission, and to create a hollow lumen within membranes [99]. In view of the known interactions of ATXN2 with endocytosis factors, it is interesting to note that ACTN1 mediates the contracting force of cortical actin-myosin complexes, which acts on clathrin lattices to internalize the vesicle [100-103]. The endocytic internalization of the ADORA2A (adenosine A2A) receptor and the L-type Ca-channel was shown to be dependent on calcium and excitation, in a stimulus-response mediated via the interaction of calmodulin with ACTN1 [104, 105].

The protein sequence and structure of alpha-Actinin makes it a versatile docking station for a large number of other factors. Alpha-Actinin consists of an N-terminal Calponin-Homology (CH1/2) domain that serves as an protein-protein interaction module [106], four spectrin repeats ensuring a rod-like linear shape [107], and a C-terminal Calmodulin-like domain (CaM) capable of calcium-binding and sensing [95]. Alpha-Actinin is abundantly expressed with preference in cells under the influence of mechanical force. It is subcellularly located in the cytoplasm and at the migrating edge of plasma membranes, together with other actin-binding proteins such as VCN (Vinculin), GSN (Gelsolin), CFL1 (Cofilin), PDLIM1 (PDZ And LIM Domain 1, aka Elfin) under control of kinases such as LIMK1 (LIM motif containing kinase 1) [108-110]. Alpha-Actinin is concentrated in filopodia or in extending neurites, when the growth cone extends upon stimulation by trophic factors such as the Purkinje-neuron specific c-Kit [96, 111-115].

Our findings indicate that ATXN2 directly binds to ACTN1, so it may modulate its downstream functions e.g. during dendritic spine growth.

\section{Results}

2.1. Recombinant full-length alpha-Actinin-1 and Ataxin-2 interact in co-immunoprecipitates from HEK-293 cells.

To evaluate the coexistence of ATXN2 and ACTN1 in a protein complex for mammalian cells, we used overexpressed and tagged versions of full-length ATXN2 and ACTN1 in HEK-293 cells, investigating their association via co-immunoprecipitation. We precipitated ATXN2 with an antibody against its specific tag from the cell homogenates and detected ACTN1 in the precipitate by immunoblots (WB) (Figure 1). This observation confirms the published yeast-two-hybrid results and demonstrates that both proteins can interact in mammalian cells. 


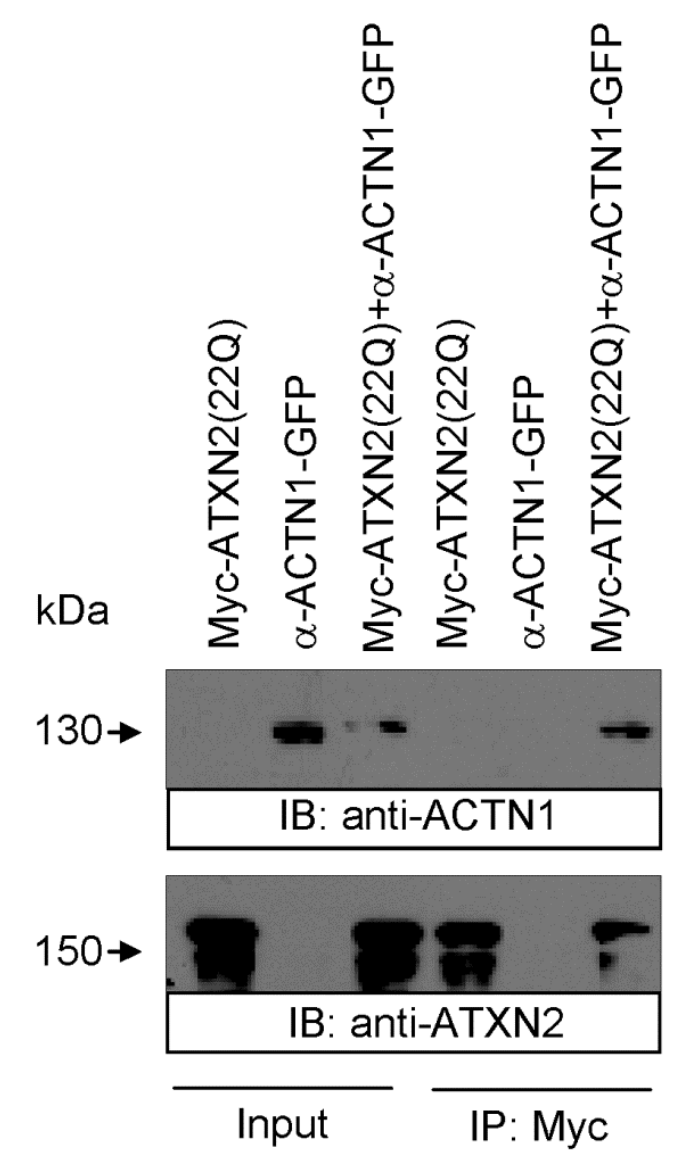

Figure 1. Recombinant Ataxin-2 and alpha-Actinin-1 form a protein complex in HEK-293 cells. Plasmids coding for Myc-tagged wildtype (22Q) ATXN2 and for GFP-tagged ACTN1 were used to co-transfect HEK-293 cells. Input was controlled in the three lanes to the left, while immunoprecipitates from cell homogenates with anti-Myc antibody are shown in the right three lanes. Precipitates were analysed by SDS-PAGE and Western blotting. The band corresponding to GFP-ACTN1 can be detected selectively in the immunoprecipitate (IP) of Myc-tagged ATXN2(22Q), indicating the presence of a protein complex that contains both components.

2.2. Endogenous ACTN1 and ATXN2 interact in co-immunoprecipitates from mouse brain cytosolic fractions.

It was important to clarify if endogenous ATXN2 and endogenous ACTN1 exist in a physiological complex within the brain, the tissue most affected by SCA2. In view of the low abundance of ATXN2, a differential velocity centrifugation protocol (Figure 2A) was used for the subcellular fractionation of mouse brain. To differentiate between cytosolic and light membrane fractions, the cytosolic marker EEA1 (Early Endosome-Associated Protein P162) and the light membrane marker CANX (endoplasmic reticulum-associated Calnexin) were used. ATXN2 and ACTN1 co-fractionated in the cytosolic fraction (Figure 2B).

Immunoprecipitation of ACTN1 from the cytosolic fraction confirmed the co-precipitation of ATXN2. Conversely, upon precipitation of ATXN2 the ACTN1 protein was detected in association with it (Figure 2C). These findings substantiate the notion that an endogenous complex containing both proteins exists in brain. 
A

\section{Total brain}

homogenate

Nuclear pellet Post nuclear SN

10000xg10min

Mitoch. pellet Post mitoch. SN

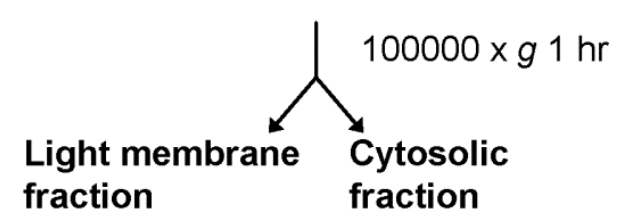

B

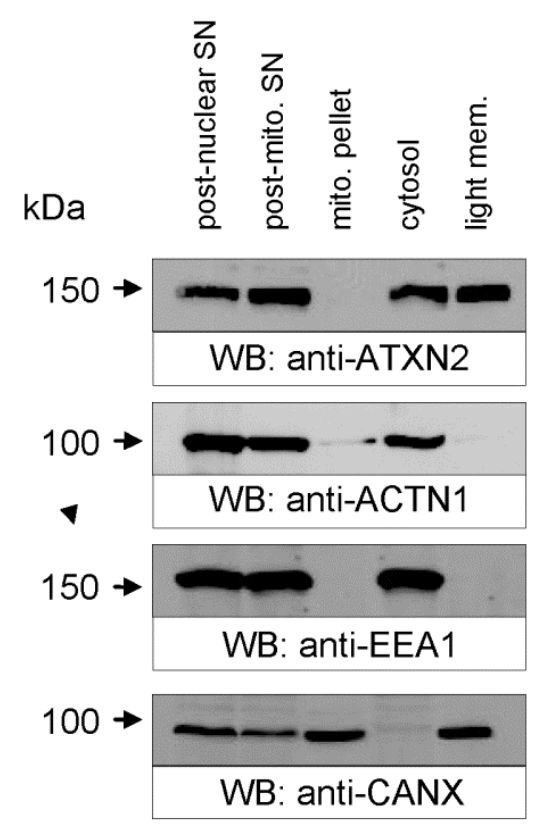

C
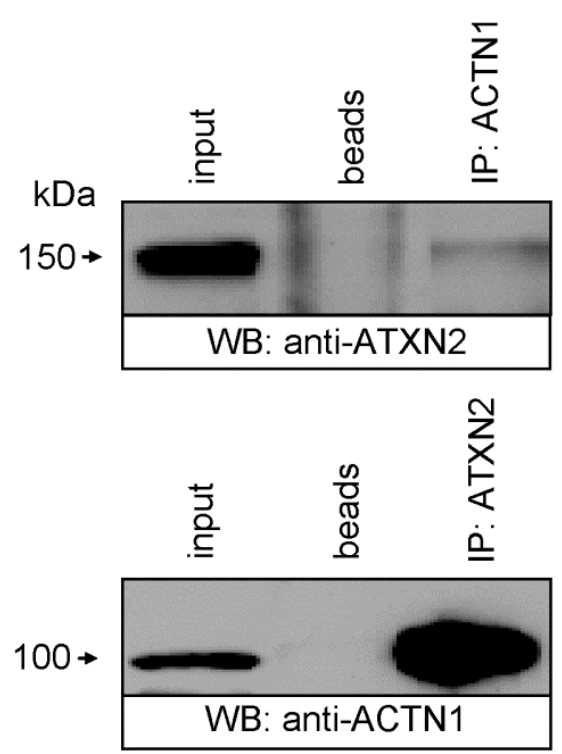
163

164

165

166

167

168

169

170

171

172

173

174

175

176

177

178

179

180

181

182

183

184

Figure 2. ATXN2 and ACTN1 form an endogenous complex in mouse brain. (A) Differential velocity centrifugation protocol for brain fractionation. (B) Among various brain fractions, ATXN2 was detected by Western blot (WB) in the post-nuclear and the post-mitochondrial supernatants (SN), but not in the mitochondrial pellet. The cytosolic fraction, indicated by the marker protein EEA1, contained both ATXN2 and ACTN1, while the light membrane fraction contained only ATXN2. (C) Co-immunoprecipitates from mouse cytosolic fraction contained both ATXN2 and ACTN1. Empty beads were used for negative controls. Analysis of the precipitates was performed by SDS-PAGE and immunodetection with the indicated antibody. ATXN2 can be demonstrated in the ACTN1 precipitate and vice versa. These data prove the existence of an endogenous complex containing both proteins in the disease-relevant tissue.

2.3. In GST-pull-down assays, the N-terminus of ATXN2 interacts with full-length ACTN1.

Recombinant constructs tagged by GST (Glutathione-S-Transferase polypeptide) were used in pull-down assays to define the domain within ATXN2, which is responsible for the interaction. Full-length ACTN1 with GST-tag was combined with Myc-tagged ATXN2, either full-length or in fragments (Figure 3A). The fragments contained (i) the N-terminus of ATXN2 as the least conserved part of the protein, (ii) the polyQ domain either only with the like-Smith-antigen (Lsm) domain or (iii) also with its Lsm-associated domain (LsmAD), or (iv) the rest of the protein containing the Pam2-motif. Binding could be observed for three of the fragments which all contained the very $\mathrm{N}$-terminal part of ATXN2 (Figure 3B). The addition of the Lsm and LsmAD domains did not have a strong effect on the interaction. The region essential for the interaction lies upstream from the polyQ region of ATXN2 in the N-terminal part. The function of this $\mathrm{N}$-terminal sequence has not been defined so far. 
A
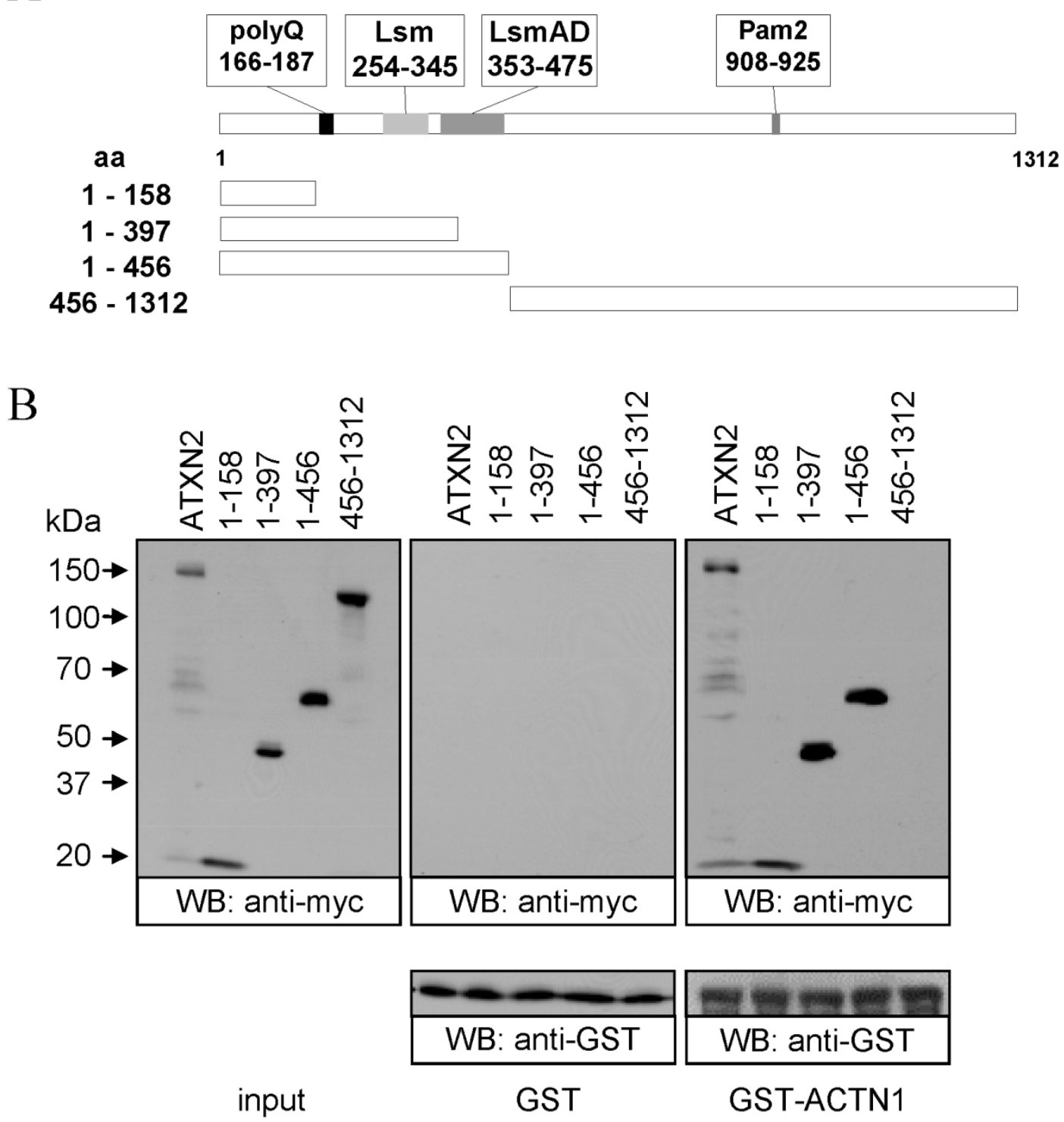

Figure 3. ATXN2 interacts with ACTN1 through its N-terminal part. (A) Schematic representation of ATXN2 fragments tested for interaction with ACTN1 in GST-pull-down assays. (B) Input was controlled in the left panel, where the translation product of each Myc-tagged ATXN2 construct was detected via the Myc-tag antibody. In the middle panels, GST alone was loaded onto glutathione (GSH)-sepharose beads, as a negative control. In the rights panels, GST-ACTN1 was loaded on GSH-sepharose beads. Loaded beads were then incubated with extracts from HEK-293 cells that overexpressed Myc-tagged constructs of ATXN2 either full-length or as the fragments shown in (A). Equal loading of the beads with GST and GST-ACTN1 was controlled by Western blots using anti-GST antibody. Detection with anti-Myc antibody showed binding between ACTN1 and all ATXN2 constructs, which encoded the full-length protein or contained the N-terminal part with amino acids (aa) 1-456.

2.4. The Actin-Binding-Domain of ACTN1 mediates the interaction with full-length ATXN2 in GST-pull-down assays.

ACTN1 contains six distinct functional domains, with repetition of two sequence motifs that are known to mediate protein-protein interactions. They include (i) the actin-binding-domain (ABD) with two Calponin-Homology motifs (CH1/2) at the N-terminus, which mediates the connection to 
203

204

205

206

207

208

209

210

211

212

scaffold for multiple protein interactions. In addition, calcium sensing occurs via a pair of EF-hand (EFh) motifs separated by a flexible linker region at the C-terminus, which provide binding sites for two $\mathrm{Ca}^{2+}$ ions and are homologous to the four EF-hand motifs in Calmodulin [116].

To determine the region on ACTN1 that mediates the interaction with ATXN2, we used GST-fusion constructs of full-length ACTN1 and of (i) the ABD, (ii) each of the four spectrin repeats, or (iii) the last two spectrin repeats together with the EF-hand region (Figure 4A). Equal binding of ATXN2 was observed for the full-length protein and for the ABD region. All other fragments of ACTN1 failed to pull down ATXN2 (Figure 4B). These data raise the possibility that ATXN2 competes with actin for the binding site on ACTN1, which would explain the actin-filament phenotype of D. melanogaster mutants of ATXN2 [79].

A
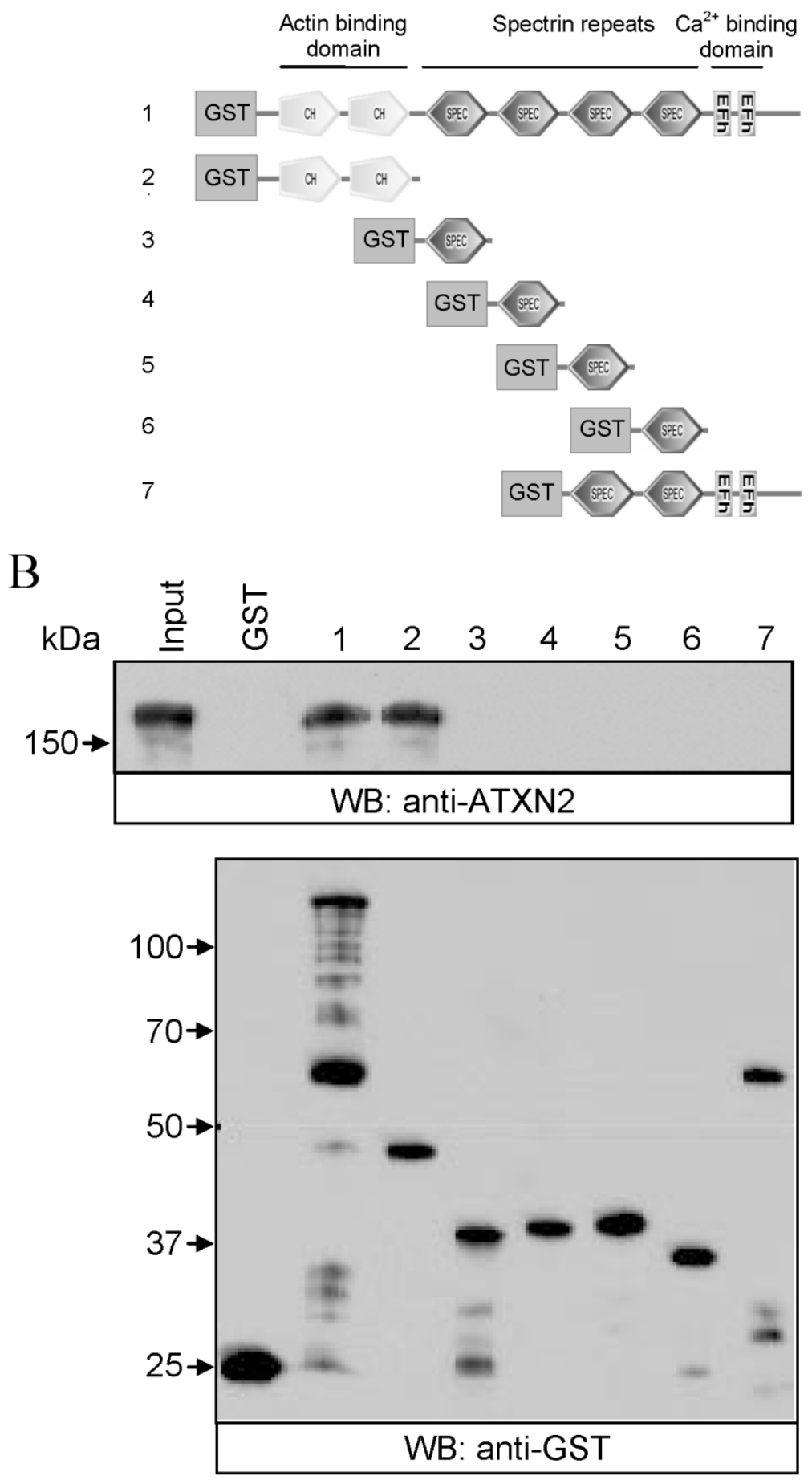
Figure 4. The N-terminal region of ACTN1 with two Calponin-Homology (CH1/2) motifs mediates the interaction with ATXN2. (A) Schematic representation of ACTN1 fragments that were tested for interaction with ATXN2 in GST pull-down assays. (B) GST-ACTN1 full-length and its GST-tagged fragments were bound to GSH-sepharose beads, which were then incubated with extracts from HEK-293 cells that overexpressed Myc-tagged full-length ATXN2. Equal loading of GST and the GST fusion proteins was controlled by an anti-GST antibody. Associated ATXN2 fragments were detected using anti-Myc antibody. ATXN2 was observed to bind to full-length ACTN1 or to the CH1/2 domain alone, in similar intensity. All other parts of ACTN1 failed to pull down ATXN2.

2.5. The pathological expansion of ATXN2 does not detectably alter the interaction in GST-pull-down assays. It is crucial to investigate if a polyQ expansion in ATXN2 affects its binding to ACTN1. We used the largest expansion observed so far in the Cuban SCA2 population, where 79Q instead of 22Q triggered disease manifestation already at 2 years and caused death by 8 years of age [1, 9]. The two N-terminal ATXN2 fragments that had bound to ACTN1 were modified to contain 79Q, instead of the preexisting $22 \mathrm{Q}$ wildtype version (Figure $5 \mathrm{~A}$ ). This expansion size had no obvious effect on the binding to ACTN1 under the current GST pull-down conditions (Figure 5B), a disappointing finding in view of the proximity between the polyQ domain and the ACTN1-binding area within ATXN2, and given the high probability that an expansion would cause N-terminal misfolding. However, in a separate manuscript we showed that a $100 \mathrm{Q}$ expansion knocked into mouse Ataxin-2 triggers authentic SCA2 [53]. The investigation of spinal cord tissue from such Atxn2-CAG100-KnockIn mice at the age of 12 months via global transcriptome profiling and automated bioinformatics demonstrated significant dysregulations of several pathways under control of actin and alpha-actinin [61]. 

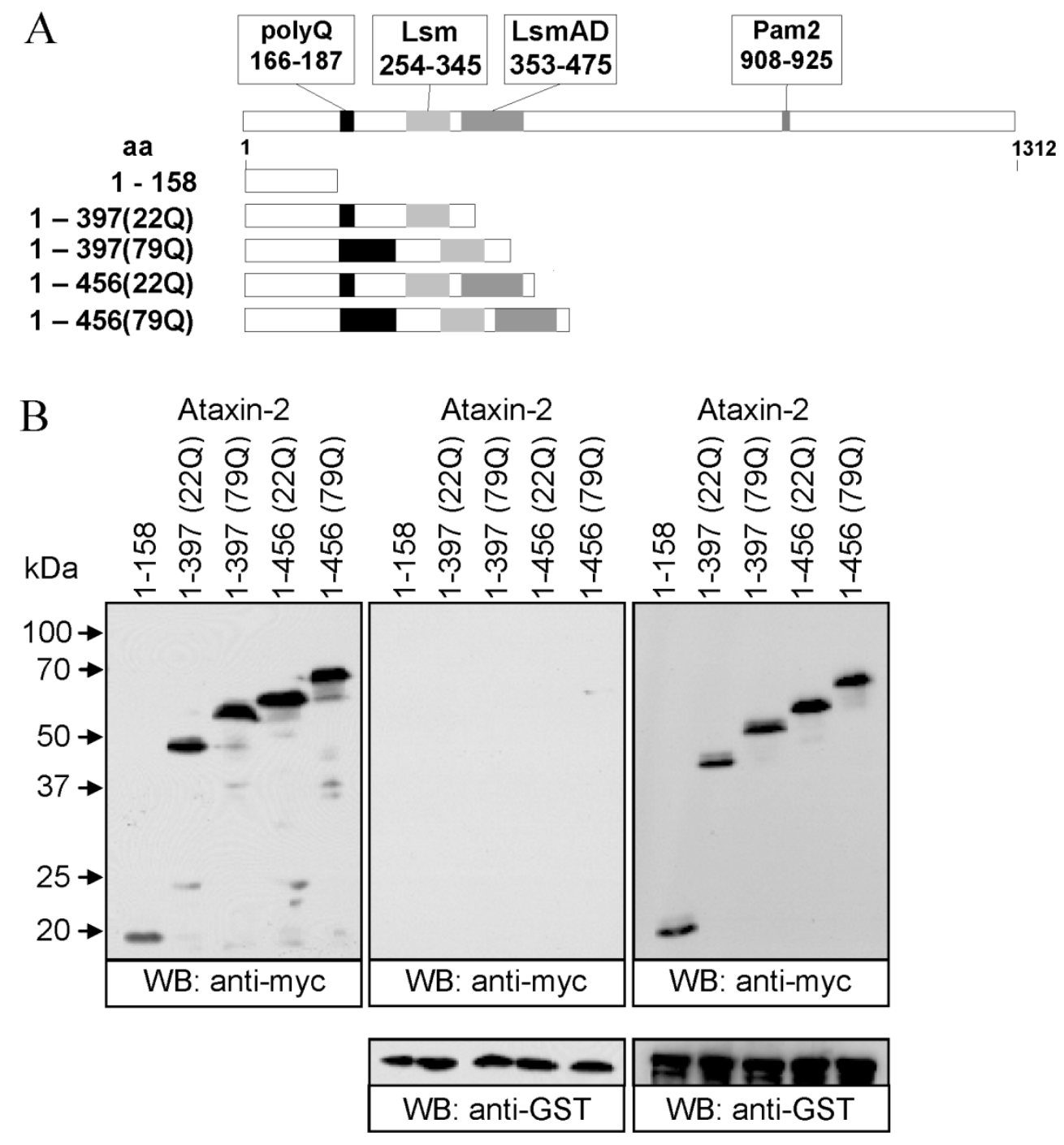

Input

GST

GST-ACTN1

Figure 5. PolyQ expansion from $22 \mathrm{Q}$ to $79 \mathrm{Q}$ has no apparent effect on the interaction between ACTN1 and ATXN2 in GST pull-down assays. (A) Schematic representation of ATXN2 fragments tested for interaction with ACTN1. (B) Correct expression of all fragments was controlled as input (left panel). GST alone (middle panel) or GST-ACTN1 (right panels) were bound to GSH-sepharose beads. The beads coupled to GST or GST-ACTN1 were then incubated with extracts from HEK-293 cells that overexpressed Myc-tagged constructs of ATXN2 fragments with normal or expanded polyQ stretches as shown in (A). The N-terminal fragment upstream from the polyQ stretch was included as a positive control. Binding of the ATXN2 fragments was detected using anti-Myc antibody, binding and equal amounts of GST and GST-ACTN1 were confirmed with the anti-GST antibody. All fragments bound to GST-ACTN1. The expansion of the polyQ stretch did not visibly alter the binding of the ATXN2 fragments to GST-ACTN1.

2.6. Co-localization of ATXN2 and ACTN1 as recombinant proteins in COS-7 cells, and as endogenous proteins in rat hippocampal neurons.

In order to substantiate the biochemical findings, the subcellular localization of both proteins was examined further. Again with the recombinant constructs already used during co-immunoprecipitation experiments (Figure 1), ATXN2 and ACTN1 were overexpressed in COS-7 
both regions. There was no apparent difference between the co-localisation of normal ATXN2 (22Q) and ACTN1 compared to the mutated form of ATXN2 (79Q) (Figure 6A). To also visualize this co-localisation for both endogenous proteins, as further confirmation of the co-immunoprecipitation results, rat hippocampal primary neurons were stained. Indeed, a co-localisation in the cytosol could be observed (Figure 6B). These data support the biochemical findings and corroborate the physiological existence of a ATXN2 / ACTN1 complex.

\section{A}

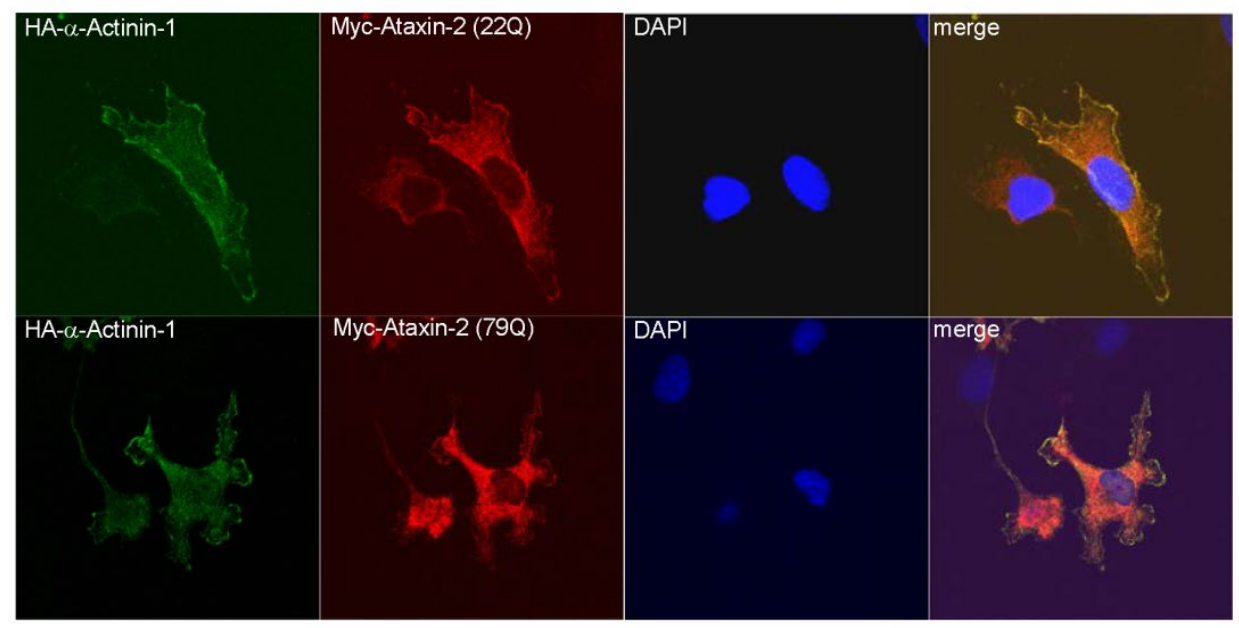

\section{B}
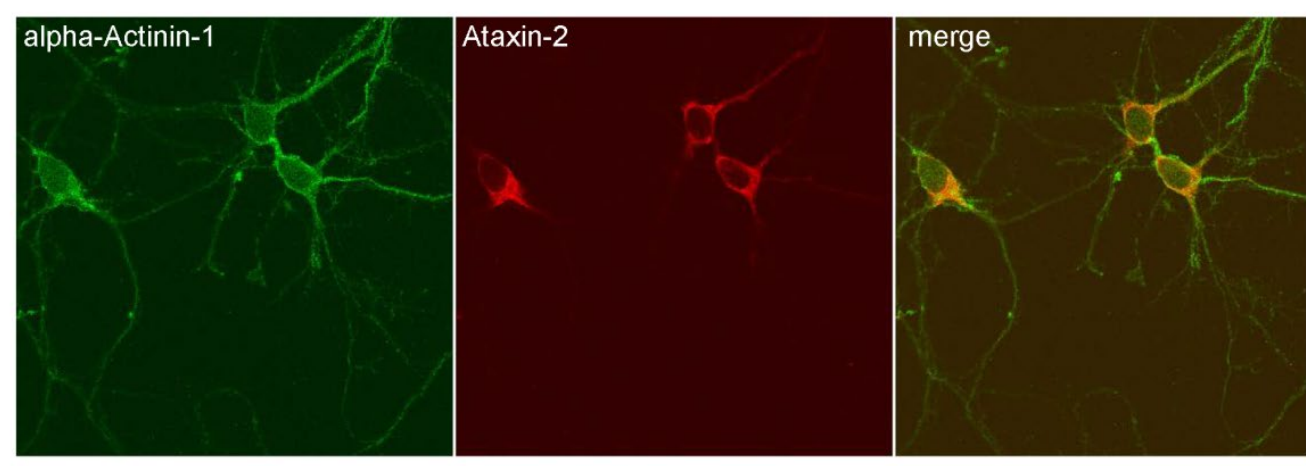

Figure 6. ACTN1 co-localizes with ATXN2 upon confocal microscopy. (A) COS-7 cells were transfected with HA-ACTN1 (green) and either Myc-ATXN2(22Q) or Myc-ATXN2(79Q) (red); they were counterstained with DAPI (blue) to illustrate the nucleus. Each of the recombinant proteins was detectable throughout the cytosol with perinuclear concentration and the plasma membrane. In the merged pictures, the co-localization of the recombinant proteins appears in yellow. A distinct yellow co-localization signal was demonstrated at the leading cell growth edge, where plasma membrane cortical actin is concentrated. (B) In rat hippocampal neurons, endogenous ACTN1 (green) and ATXN2 (red) were stained, showing a diffuse cytosolic pattern for both proteins, with ATXN2 being less abundant in neurites than ACTN1. Specific signals at the plasma membrane were not obvious under non-overexpressed conditions, in the absence of growth factor deprivation. In the merged picture, the co-localization (yellow) was prominent in the perinuclear cytosol.

\section{Discussion}

This study examines the direct protein-protein interaction between Ataxin-2 and alpha-Actinin-1. We demonstrated that ATXN2 and ACTN1 associate in mammalian cells, 
showed in GST-pulldown assays what specific domains in each factor are responsible for the interaction, and corroborated the coexistence of the endogenous proteins by differential fractionation and with microscopy, studying brain tissue and neurons as the principal targets of the relevant disease process.

So far, interactions and associations of ATXN2 to various proteins suggested two major roles for ATXN2 in cell physiology. On the one hand they included a quality control function for RNAs [74, 76, 80-82], on the other hand an inhibition of the RTK endocytosis process [82], in particular during cell stress. We now present data that support previous findings in $D$. melanogaster regarding the impact of ATXN2 on the actin-cytoskeleton [79]. The loss-of-function of Datx2, the single fly homolog of mammalian ATXN2 and ATXN2L, resulted in severe phenotypic consequences. Datx2 was found to be a dosage-sensitive regulator of actin filaments, affecting fly bristle formation and actin in eye-discs, in absence of a direct actin-interaction. Actin synthesis and abundance was not altered. Thus, the interaction of ATXN2 with ACTN1 may partially explain how cortical actin in growth processes is affected by mutations in Ataxin-2.

Our data also expand on a previous report that ATXN2 as well as Huntingtin interact directly with endophilin A1/A3 (SH3GL2/SH3GL3) and co-immunoprecipitates also with L-/T-Plastin (homologs of I-Plastin aka Fimbrin) in mouse brain [82]. This association was discovered because an unbiased survey of polyQ toxicity in yeast had identified the Fimbrin depletion to trigger vulnerability towards ATXN2, Huntingtin, Endophilin A1 and A3. The resulting growth deficit could be rescued by human L- and T-Plastin. This study also showed that a direct ATXN2-Plastin interaction was not detectable in yeast-two-hybrid assays, but ATXN2 overexpression in the mammalian cell lines HEK-293, SH-SY5Y and COS-1 led to higher T-Plastin (protein symbol PLS3) abundance upon immunofluorescence imaging [82]. As shown in Figure 7, both T- and L-Plastin have CH1/2 domains for actin-association in common with ACTN1, as well as sharing two EFh domains. L-/T-Plastin are actin-bundling proteins like alpha-actinins [95], control the distance between actin filaments and influence cell morphology $[117,118]$. Indeed, alpha-actinins can prevent Fimbrin from actin-association [119, 120]. Although the identification of a specific domain that mediates the association between L-/T-Plastin and ATXN2 has not been possible, our data suggest that the actin-binding-domain could be involved again.
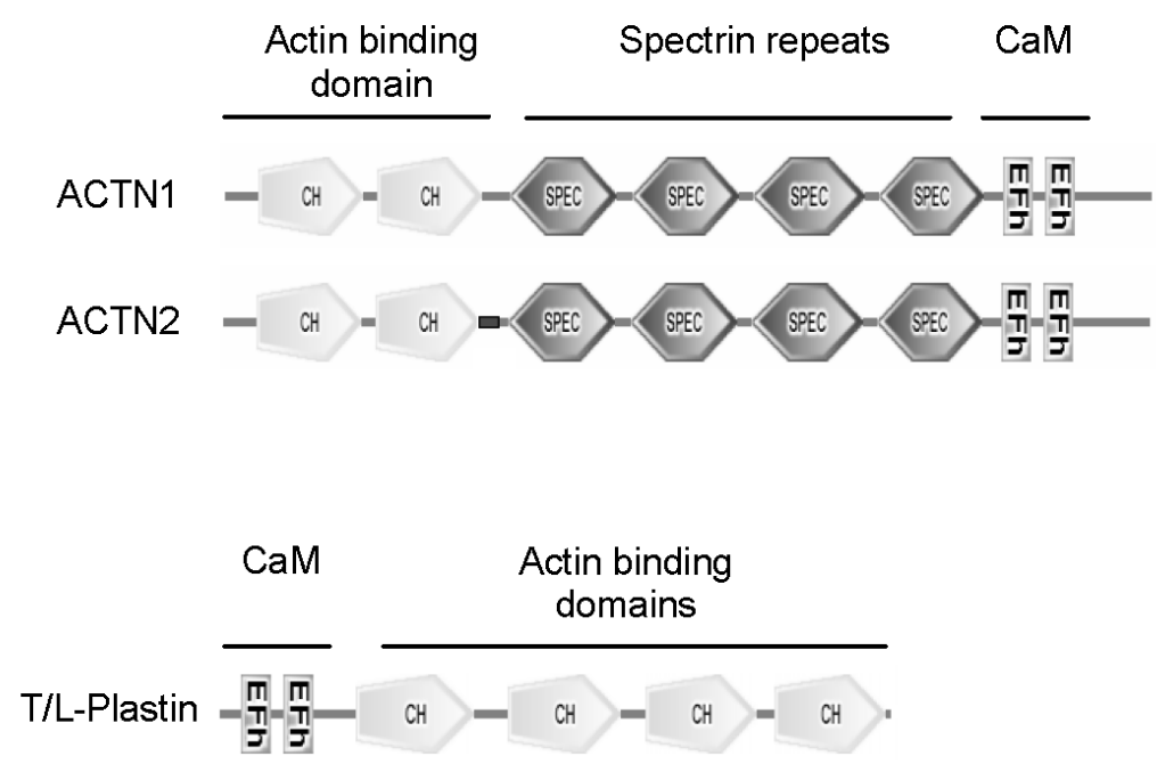
Figure 7. Alpha-Actinin-1 and T-/L-Plastin share the actin-binding-domain with two $\mathrm{CH}$ motifs, as well as the $\mathrm{Ca}^{2+}$ binding domain $(\mathrm{CaM})$ with two EF-hand motifs, but differ in the order and number of these domains. Alpha-Actinins additionally possess a rod domain consisting of spectrin repeats.

It is important to note that the force needed to perform endocytosis depends on the actin cytoskeleton together with myosin motors [121-123]. Thus, our findings also expand previous reports that Proline-rich-domains (PRD) in ATXN2 interact with SH3 motifs within proteins of the endocytosis apparatus (such as SH3GL2, SH3GL3, SRC, GRB2) to slow the internalization of growth factor receptor tyrosine kinases (RTK). This interactions modulates growth/stress signalling via phosphorylation cascades, probably including the mTORC1 complex that controls cell size [56, 72, 73, 124-129]. ATXN2 may therefore control such plasma membrane uptake events at two sites, on the one hand for ultrafast clathrin-independent endocytosis during vesicle neck formation and scission via Endophilin-A [130-132], on the other hand for clathrin-dependent endocytosis during the slow internalization process and scission via ACTN1 with T-Plastin as modifiers of actin stabilization [133-135]. However, it is important to note that the ATXN2 interaction with ACTN1 might not only modulate actin-interactions, since some ABD motifs were reported to have roles as microtubule-binding site and as signalling scaffold [136, 137]. There is also an ongoing debate about the physiological role of the poorly conserved N-terminal region of ATXN2 upstream from the polyQ domain encoded within exon-1. One start codon initiates the ATXN2 reference sequence that includes a N-terminal PRD motif (aa 118-123), but an alternative start codon exists just before the polyQ sequence. The Lsm/LsmAD motifs encoded by exons 3-8 and the Pam2 motif encoded by exon-16 are constitutively expressed. In contrast, the second PRD motif (aa 588-593) is encoded by the alternatively spliced exon-10 [125, 138]. The functional consequences of these isoforms of ATXN2 remain to be elucidated.

Although clear evidence was observed for the physiological occurrence of the AXTN2/ACTN1 protein complex, the GST-pull-down experiments failed to demonstrate an obvious impact of the polyQ expansion on this association. It is therefore crucial to discuss recent observations during the characterization of our Atxn2-CAG100-KnockIn mouse mutant, which represents an authentic SCA2 model [53, 56, 61]. The global transcriptome profile in spinal cord at incipient versus terminal disease stages consistently showed expression dysregulations in opposite directions for two main surveillance mechanisms: Firstly, the expression upregulations concerned PABPC1 and other RNA toxicity control factors, together with activations of innate immunity, microgliosis and lysosomal activation. Secondly, the expression downregulations reflected metabolic deficits, lipid depletion and demyelination. Automated bioinformatics analyses revealed significant enrichments mainly for the pathway "regulation of actin cytoskeleton" (with dysregulation of several members of the FGF family and their receptors, prominent upregulation of Myl1, upregulations also for the ACTN1-interactors $\mathrm{Vcl}$ and Gsn, as well as downregulations for Myh10 and Limk1, downstream Rras, and several components of Pi3k signalling with Mapk6), pathway "EGFR1 signaling", pathway "Insulin signaling", pathway "Focal adhesion-Pi3k-Akt-mTOR-signals", pathway "MAPK signalling", and pathway "Calcium regulation" (Suppl. Tables S6/S7 in [61]). This was accompanied by significant downregulations of clathrin-dependent RTK endocytosis factors such as Ntrk2, Erbb3, Fgfr2, Fgfr3, Fgf12, Insig1, Aak1, Ttbk1, Ttbk2 and the ACTN1 interactor mRNA Pdlim1 (Suppl. Tables S5 in [61]). Thus, at least in mouse nervous tissue with prolonged observation over years, a polyQ expansion to 100Q in ATXN2 appears to affect the pathways that are connected to ACTN1 function.

The most prominent pathology of SCA2 appears as progressive rarefication in the dendritic trees of the large cerebellar Purkinje neurons [23, 139], whose main afferents are glutamatergic from the local granule neurons. In addition, the SCA2 disease process is quite similar to ALS in affecting spinal motor neurons and their glutamatergic monosynaptic input from cortical motor neurons 
359

360

361

362

363

364

365

366

367

368

369

370

371

372

373

374

375

376

377

378

379

380

381

382

383

384

385

386

\section{7}

388

389

390

391

392

393

394

395

396

397

398

399

400

401

402

403

404

405

406

407
[39-41, 43, 44, 140]. In both preferentially affected regions, glutamatergic presynapses modulate the trophic state of postsynaptic spines. It is therefore noteworthy that the subunit GluR4 of the glutamatergic AMPA receptor interacts directly with ACTN1 and is regulated in a phosphorylation dependent manner [141, 142]. In addition, ACTN1 interacts with the metabotropic glutamate receptor mGluR5b and regulates its surface expression and function [143]. Finally, ACTN1 modulates the interactions of CAMK2, the crucial factor for postsynaptic spine plasticity in glutamatergic synapses [144-146]. Other alpha-actinins were reported to play an important role in the nervous system for synaptic plasticity and spine morphology [147, 148] via regulation of the NMDA receptor [149, 150]. Alpha-actinin-4 was shown to be crucial when the activation of growth factor receptor tyrosine kinases (RTK) triggers actin-remodelling and macropinocytosis in a calcium-dependent process called circular ruffling [112, 151-154].

The role of alpha-actinins in other neurodegenerative diseases has already been substantiated. In polyQ-expansion triggered Huntington's disease, decreased abundance of ACTN2 and specific subunits of the glutamatergic NMDA receptor were observed in hippocampal tissue [155], and microscopy as well as proximity ligation assays demonstrated the expanded disease protein Huntingtin to associate with ACTN1 / VCL (Vinculin) in stress fibers, membrane ruffles and lamellar protrusions [156]. Protein aggregates of actin and alpha-actinins have been described under the name of "Hirano bodies" in patients with age-associated neurodegenerative disorders, such as ALS, FTLD (aka Pick's disease), Parkinsonism-Dementia complex, Alzheimer's disease and Creutzfeld-Jakob disease [157, 158]. It is interesting to note that alpha-actinin dysfunction also has an impact on the trophic state of muscle tissue after immobilization and denervation [159], given that SCA2 patients early on suffer from muscle cramps and preterminally suffer from massive muscle atrophy.

Altogether, in view of the known interactions of ATXN2 with Endophilins A1/A3 as well as T- and L-Plastin, our new observations suggest that ATXN2 may modulate the slow endocytic internalization of growth factor receptors, neurotransmitter receptors and ion channels in dendritic spines via ACTN1 binding and actin filament remodelling.

\section{Materials and Methods}

Mouse breeding

The animal experiments were revised by the Regierungspräsidium Darmstadt with approval code V54-19c20/15-FK/1083. Breeding was performed as previously reported [160-162].

\section{Cell culture}

Monkey COS-7 (CRL-1651 from ATCC, Manassas, VA, USA) and human HEK-293 cells (CRL-1773 from ATCC, Manassas, VA, USA) were grown in Dulbecco's modified Eagle medium (DMEM) supplemented with $10 \%$ fetal calf serum, $2 \mathrm{mM}$ glutamine and antibiotics (all Gibco/Invitrogen, Waltham, MA, USA) at $37^{\circ} \mathrm{C}$ and $5 \% \mathrm{CO}_{2}$. Prior to passaging the cells were washed with Phosphate-buffered-saline (PBS) prewarmed to $37^{\circ} \mathrm{C}$. To detach the cells, a solution with $0.25 \%(w / v)$ Trypsin and $0.53 \mathrm{mM}$ EDTA was used.

\section{Transient transfection of COS-7 and HEK-293 cells.}

Cells were grown to an optical confluency of $75 \%$ and then transfected with recombinant tag-constructs of ATXN2 [73] and ACTN1 (provided by Erich Wanker, Berlin) using Lipofectamine 2000, according to the manufacturer's instructions.

\section{Rat hippocampal neurons}

Day 18 embryonic Sprague/Dawley rat hippocampal neurons were purchased from Genlantis (San Diego, CA, USA). The neurons were cultured in Neurobasal medium, B27 serum-free 
supplement and glutamax (Invitrogen, Carlsbad, CA, USA) on poly-D-lysine (Sigma, St. Louis, MI, USA) coated coverslips.

Preparation of Protein Extracts from transfected cells.

Transfected cells were washed in ice-cold PBS and lysed for $20 \mathrm{~min}$ in a lysis buffer containing $50 \mathrm{mM}$ Hepes-NaOH, pH 7.5, $150 \mathrm{mM} \mathrm{NaCl}, 1 \mathrm{mM}$ EDTA, 10\% glycerol, 0.1\% Igepal CA-630, protease inhibitor cocktail, $1 \mathrm{mM}$ PMSF, $1 \mathrm{mM} \mathrm{Na}_{3} \mathrm{VO}_{4}$, and $1 \mathrm{mM} \mathrm{NaF}$. Cell debris and insoluble material was removed by centrifugation at $20000 \mathrm{xg}$ and $4{ }^{\circ} \mathrm{C}$. The supernatant was stored at $-80{ }^{\circ} \mathrm{C}$ for co-immunoprecipitation experiments.

\section{Immuncytochemistry.}

Either COS-7 cells or rat hippocampal neurons were grown on $12 \mathrm{~mm}$ glass coverslips in 24 well plates. Optional transfection of COS-7 cells was carried out with Lipofectamine 2000 according to the manufacturer's instructions. Either $24 \mathrm{hr}$ past transfection (COS-7) or after seven days in culture (rat hippocampal neurons) cells were fixed at room temperature in $4 \%$ paraformaldehyde for $20 \mathrm{~min}$. Cells were washed three times with PBS and incubated with $0.5 \%$ TritonX-100 and 5\% Chemiblocker (Chemicon, Temecula, CA, USA) to permeabilize the cells and to block unspecific binding. Incubation with the primary antibody was $1 \mathrm{hr}$ at room temperature followed by three washing steps. Myc-ATXN2 was detected using anti-Myc Ig (Clontech/Takara, Heidelberg, Germany, 1:1000), while HA-ACTN1 was detected using anti-HA Ig (Clontech/Takara, Heidelberg, Germany, 1:1000). The endogenous proteins were detected with a mouse antibody against ATXN2 (BD Biosciences, San Jose, CA, USA, titer 1:100) and a rabbit antibody against ACTN1 (Santa Cruz, Dallas, TX, USA, titer 1:50). The secondary antibody was applied for $1 \mathrm{hr}$ under light protection. Alexa 546-conjugated anti-mouse immunoglobulin (Ig) (Molecular Probes, Eugene, OR, USA) and Alexa 488 conjugated anti-rabbit Ig (Molecular Probes, Eugene, OR, USA) were used (titer 1:1000). After three washing steps, the cells were mounted using ProLong Antifade reagent (Molecular Probes/Invitrogen, Eugene, OR, USA). DAPI was from Invitrogen (Carlsbad, CA, USA). Pictures were taken on a Zeiss LSM 510 confocal microscopy System.

\section{Preparation and purification of GST-fusion proteins.}

Glutathion-S-transferase (GST) -fusion proteins were transformed into BL21-Gold E.coli (Stratagene, La Jolla, CA, USA). $10 \mathrm{ml}$ of starter culture were inoculated into $250 \mathrm{ml}$ 2xYTA medium and grown to an $\mathrm{OD}_{600}$ of 0.6-0.8. Induction was carried out with $0.25 \mathrm{mM}$ IPTG for $4 \mathrm{hr}$ at $37^{\circ} \mathrm{C}$. Cells were harvested at $3000 \mathrm{xg}$ in a swinging bucket centrifuge. The pellets were resuspended in TEN (50 mM Tris 7.5; $0.5 \mathrm{mM}$ EDTA; $0.3 \mathrm{mM} \mathrm{NaCl}$ ). Then $10 \mathrm{mg}$ lysozyme and $4 \mathrm{mM}$ DTT were added and the suspension was incubated on ice for $15 \mathrm{~min}$. Subsequently, $200 \mu \mathrm{l}$ of $10 \% \mathrm{NP}-40$ were added and the suspensions were stored overnight at $-80 \%$. Finally, $15 \mathrm{ml} \mathrm{NaCl}-\mathrm{Mg}(1.5 \mathrm{M} \mathrm{NaCl}$; $12 \mathrm{mM} \mathrm{MgCl} 2)$ and $100 \mu \mathrm{g}$ DNase were added, followed by incubation over $1 \mathrm{hr}$ on ice. Debris and membranes were pelleted at 20,000 $\mathrm{xg}$ with $4{ }^{\circ} \mathrm{C}$ in a Sorvall-centrifuge. The supernatants were analysed by SDS-PAGE with Western blotting and stored at $-80^{\circ} \mathrm{C}$.

\section{In vitro Protein Binding Experiments.}

Glutathione-sepharose 4B (Amersham Biosciences, Piscataway, NJ, USA) was loaded with GST-fusion proteins for $1 \mathrm{hr}$ at $4^{\circ}$ with end-over-end rotation. Protein loaded beads were washed with binding buffer (50 mM HEPES-NaOH, pH 7.5, $150 \mathrm{mM} \mathrm{NaCl}, 2 \mathrm{mM} \mathrm{MgCl}$, 1 mM DTT, 5\% glycerol, 0.01\% Igepal CA-630, protease inhibitor cocktail, $1 \mathrm{mM} \mathrm{PMSF}, 1 \mathrm{mM} \mathrm{Na} \mathrm{VO}_{4}, 1 \mathrm{mM} \mathrm{NaF}$ ). Cell lysates were added and incubated at $4^{\circ} \mathrm{C}$ for $4 \mathrm{hr}$ with end-over-end rotation. Following the incubation, five washing steps with 5 volumes of binding buffer were made and bound proteins were eluted by boiling in SDS sample buffer. The samples were analysed by SDS-PAGE with Western blots. The GST-antibody was obtained from Amersham Biosciences (Piscataway, NJ, USA). 
Freshly dissected mouse brain was disrupted with a Dounce homogeniser in $5 \mu \mathrm{l}$ homogenisation buffer $(0.25 \mathrm{M}$ sucrose, $50 \mathrm{mM}$ Tris- $\mathrm{HCl}, \mathrm{pH} 7.5,25 \mathrm{mM} \mathrm{KCl}, 5 \mathrm{mM} \mathrm{MgCl}$, protease inhibitor cocktail, $1 \mathrm{mM}$ PMSF, $1 \mathrm{mM} \mathrm{Na} \mathrm{VO}_{4}, 1 \mathrm{mM} \mathrm{NaF}$ ) per mg wet weight. Separation of cellular organelles by differential velocity centrifugation followed exactly a reported protocol [163] as shown in figure $4 \mathrm{~A}$, which yielded fractions that predominantly contained nuclei, mitochondria/heavy membranes, light membranes/polysomes, and cytosol. The cytoplasm fraction was concentrated using a centrifugal Amicon Ultra 5.000 MWCO (Millipore) at $4{ }^{\circ} \mathrm{C}$. The light membrane fraction was resuspended in binding buffer (25 mM HEPES-NaOH, pH 7.5, $150 \mathrm{mM} \mathrm{NaCl}, 2 \mathrm{mM} \mathrm{MgCl}, 1 \mathrm{mM}$ DTT, 5\% glycerol, 0.01\% Igepal CA-630, protease inhibitor cocktail, 1 mM PMSF, 1 mM Na3VO, 1 $\mathrm{mM} \mathrm{NaF}$ ) and then centrifuged at $16,000 \mathrm{xg}$ for $15 \mathrm{~min}$ at $4{ }^{\circ} \mathrm{C}$. The supernatant was stored at $-80{ }^{\circ} \mathrm{C}$ for co-immunoprecipitaion assays.

\section{Co-immunoprecipitation.}

Protein extracts were incubated with appropriate amounts of antibodies for at least $12 \mathrm{hr}$ at $4{ }^{\circ} \mathrm{C}$ with end-over-end rotation. Antibody-protein complexes were precipitated with Protein G-PLUS agarose (Santa Cruz Biotechnology, Heidelberg, Germany) at $4^{\circ} \mathrm{C}$ overnight. The agarose beads were sedimented by centrifugation at $1500 \mathrm{xg}$ and extensively washed with ice-cold lysis buffer. The bead sediment was boiled in SDS sample buffer or non-reducing sample buffer (Pierce, Rockford, IL, USA), and the supernatant was analysed by SDS-PAGE and Western blotting.

\section{Conclusions}

(i) Previously reported yeast-two-hybrid findings on direct protein-protein-interaction, (ii) current data on the co-sedimentation, co-localization and co-immunoprecipitation in mammalian cells, and (iii) recent literature on pathomechanisms in a SCA2 mouse model are consistent and indicate that the association of the mutant N-terminus of ATXN2 with the actin-binding-domain of ACTN1 contributes to the trophic deficits of dendritic spines in affected neurons.

\section{Supplementary Materials: Supplementary materials can be found at www.mdpi.com/xxx/s1.}

Author Contributions: Conceptualization, J.N. and G.A.; methodology, F.E. and D.F.N.; software, F.E. and J.N.; validation, N.E.S.; formal analysis, J.N.; investigation, F.E., D.F.N., J.N. and G.A.; resources, G.A.; data curation, G.A.; writing-original draft preparation, F.E. und J. N.; writing-review and editing, G.A.; visualization, F.E. and J.N.; supervision, J.N. and G.A.; project administration, G.A.; funding acquisition, G.A.

Funding: This research was funded by the Deutsche Forschungsgemeinschaft, grant numbers AU96/9-1 and AU96/11-3.

Acknowledgments: We are grateful for the technical assistance of Mekhman Azizov in Frankfurt. Plasmids were provided by Prof. Erich Wanker (Berlin, Germany).

Conflicts of Interest: The authors declare no conflict of interest. The funders had no role in the design of the study; in the collection, analyses, or interpretation of data; in the writing of the manuscript, or in the decision to publish the results.

\begin{tabular}{ll}
\multicolumn{2}{l}{ Abbreviations } \\
${ }^{\circ} \mathrm{C}$ & degree Celsius (temperature) \\
$22 \mathrm{Q}$ & 22 consecutive glutamines \\
$\mathrm{A} 2 \mathrm{BP} 1$ & Ataxin-2-binding protein 1 (aka RBFOX1) \\
aa & amino acids \\
Aak1 & mouse mRNA for AP2-Associated Protein Kinase 1 \\
ABD & Actin-Binding-Domain \\
ACTN1 & Alpha-Actinin-1 \\
AD & Alzheimer's disease \\
ADORA2A & Adenosine receptor A 2 alpha \\
Akt & Proto-Oncogene C-Akt (aka Protein Kinase B) \\
ALS & Amyotrophic Lateral Sclerosis
\end{tabular}




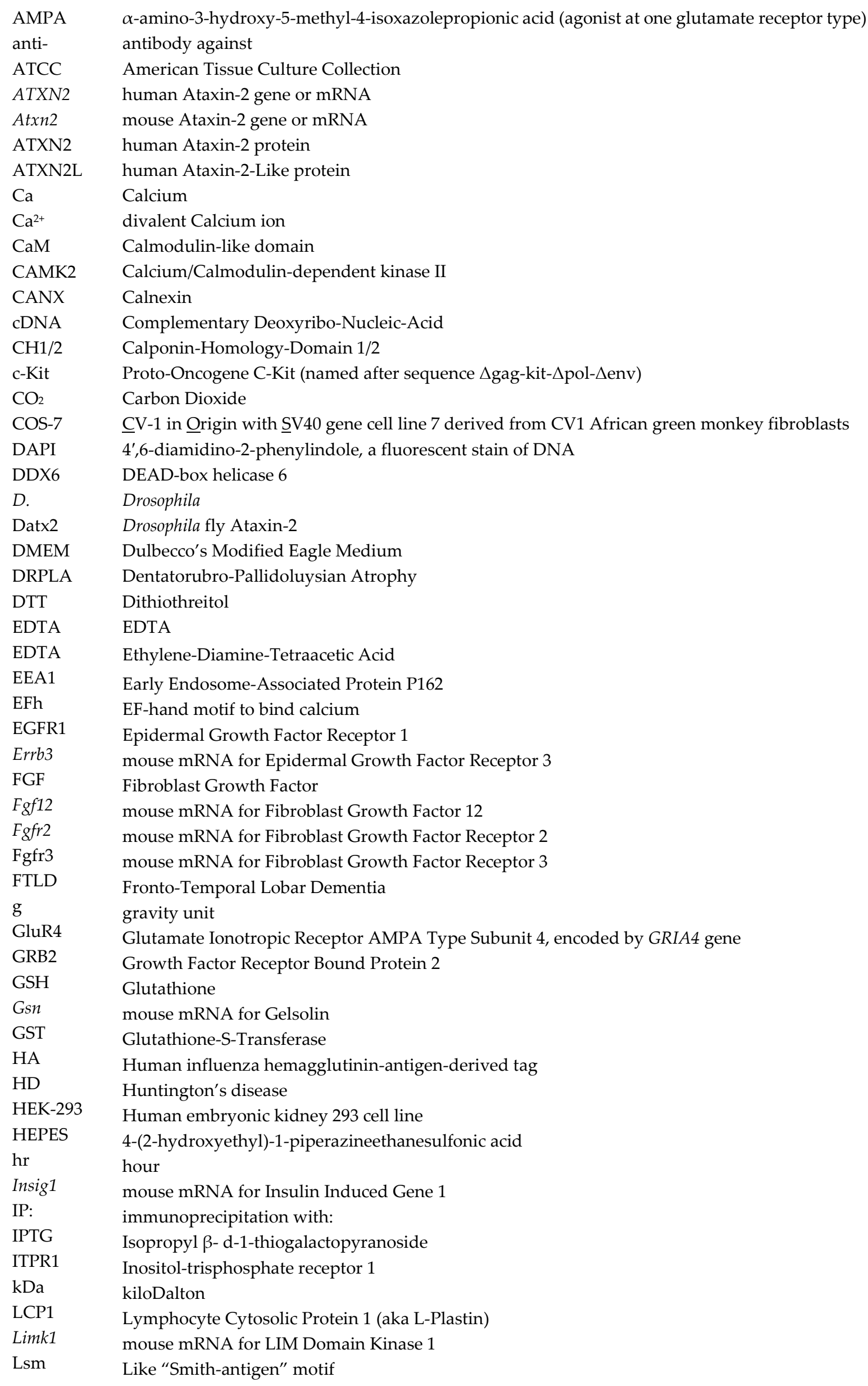




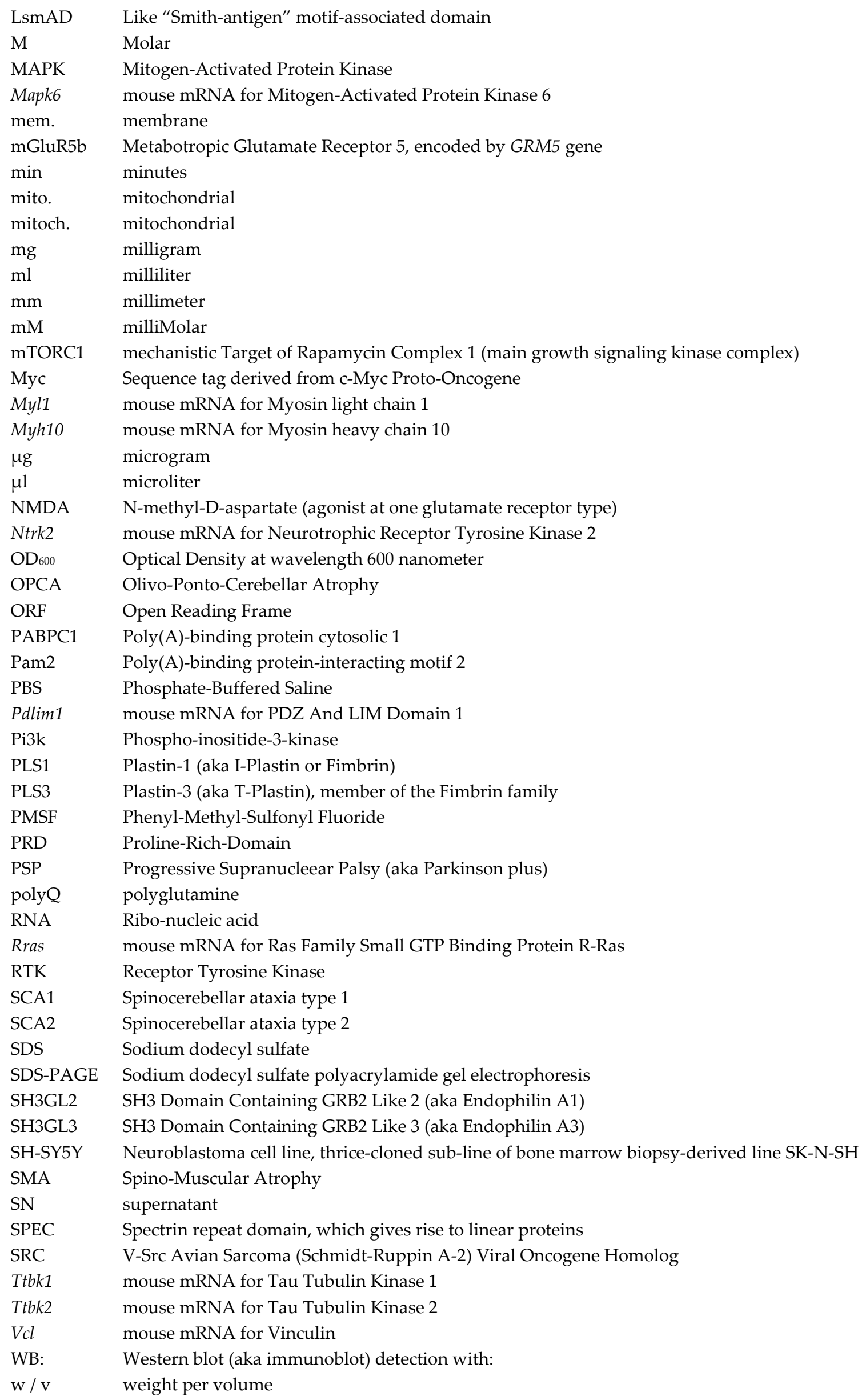


YTA Yeast Tryptone medium with Ampicillin

xg multiple of earth gravity

\section{References}

1. Pulst, S. M.; Nechiporuk, A.; Nechiporuk, T.; Gispert, S.; Chen, X. N.; Lopes-Cendes, I.; Pearlman, S.; Starkman, S.; Orozco-Diaz, G.; Lunkes, A.; DeJong, P.; Rouleau, G. A.; Auburger, G.; Korenberg, J. R.; Figueroa, C.; Sahba, S., Moderate expansion of a normally biallelic trinucleotide repeat in spinocerebellar ataxia type 2. Nature genetics 1996, 14, (3), 269-76.

2. Sanpei, K.; Takano, H.; Igarashi, S.; Sato, T.; Oyake, M.; Sasaki, H.; Wakisaka, A.; Tashiro, K.; Ishida, Y.; Ikeuchi, T.; Koide, R.; Saito, M.; Sato, A.; Tanaka, T.; Hanyu, S.; Takiyama, Y.; Nishizawa, M.; Shimizu, N.; Nomura, Y.; Segawa, M.; Iwabuchi, K.; Eguchi, I.; Tanaka, H.; Takahashi, H.; Tsuji, S., Identification of the spinocerebellar ataxia type 2 gene using a direct identification of repeat expansion and cloning technique, DIRECT. Nature genetics 1996, 14, (3), 277-84.

3. Imbert, G.; Saudou, F.; Yvert, G.; Devys, D.; Trottier, Y.; Garnier, J. M.; Weber, C.; Mandel, J. L.; Cancel, G.; Abbas, N.; Durr, A.; Didierjean, O.; Stevanin, G.; Agid, Y.; Brice, A., Cloning of the gene for spinocerebellar ataxia 2 reveals a locus with high sensitivity to expanded CAG/glutamine repeats. Nature genetics 1996, 14, (3), 285-91.

4. Velazquez-Perez, L.; Seifried, C.; Abele, M.; Wirjatijasa, F.; Rodriguez-Labrada, R.; Santos-Falcon, N.; Sanchez-Cruz, G.; Almaguer-Mederos, L.; Tejeda, R.; Canales-Ochoa, N.; Fetter, M.; Ziemann, U.; Klockgether, T.; Medrano-Montero, J.; Rodriguez-Diaz, J.; Laffita-Mesa, J. M.; Auburger, G., Saccade velocity is reduced in presymptomatic spinocerebellar ataxia type 2. Clin Neurophysiol 2009, 120, (3), $632-5$.

5. Rodriguez-Labrada, R.; Velazquez-Perez, L.; Seigfried, C.; Canales-Ochoa, N.; Auburger, G.; Medrano-Montero, J.; Sanchez-Cruz, G.; Aguilera-Rodriguez, R.; Laffita-Mesa, J.; Vazquez-Mojena, Y.; Verdecia-Ramirez, M.; Motta, M.; Quevedo-Batista, Y., Saccadic latency is prolonged in Spinocerebellar Ataxia type 2 and correlates with the frontal-executive dysfunctions. Journal of the neurological sciences 2011, 306, (1-2), 103-7.

6. Rodriguez-Labrada, R.; Velazquez-Perez, L.; Auburger, G.; Ziemann, U.; Canales-Ochoa, N.; Medrano-Montero, J.; Vazquez-Mojena, Y.; Gonzalez-Zaldivar, Y., Spinocerebellar ataxia type 2: Measures of saccade changes improve power for clinical trials. Movement disorders : official journal of the Movement Disorder Society 2016, 31, (4), 570-8.

7. Velazquez-Perez, L.; Seifried, C.; Santos-Falcon, N.; Abele, M.; Ziemann, U.; Almaguer, L. E.; Martinez-Gongora, E.; Sanchez-Cruz, G.; Canales, N.; Perez-Gonzalez, R.; Velazquez-Manresa, M.; Viebahn, B.; von Stuckrad-Barre, S.; Fetter, M.; Klockgether, T.; Auburger, G., Saccade velocity is controlled by polyglutamine size in spinocerebellar ataxia 2. Annals of neurology 2004, 56, (3), 444-7.

8. Auburger, G. W., Spinocerebellar ataxia type 2. Handb Clin Neurol 2012, 103, 423-36.

9. Orozco Diaz, G.; Nodarse Fleites, A.; Cordoves Sagaz, R.; Auburger, G., Autosomal dominant cerebellar ataxia: clinical analysis of 263 patients from a homogeneous population in Holguin, Cuba. Neurology 1990, 40, (9), 1369-75.

Rub, U.; Del Turco, D.; Del Tredici, K.; de Vos, R. A.; Brunt, E. R.; Reifenberger, G.; Seifried, C.; Schultz, C.; Auburger, G.; Braak, H., Thalamic involvement in a spinocerebellar ataxia type 2 (SCA2) and a spinocerebellar ataxia type 3 (SCA3) patient, and its clinical relevance. Brain 2003, 126, (Pt 10), 2257-72. 
11. Estrada, R.; Galarraga, J.; Orozco, G.; Nodarse, A.; Auburger, G., Spinocerebellar ataxia 2 (SCA2): morphometric analyses in 11 autopsies. Acta neuropathologica 1999, 97, (3), 306-10.

12. Rub, U.; Schultz, C.; Del Tredici, K.; Gierga, K.; Reifenberger, G.; de Vos, R. A.; Seifried, C.; Braak, H.; Auburger, G., Anatomically based guidelines for systematic investigation of the central somatosensory system and their application to a spinocerebellar ataxia type 2 (SCA2) patient. Neuropathology and applied neurobiology 2003, 29, (5), 418-33.

13. Rub, U.; Burk, K.; Schols, L.; Brunt, E. R.; de Vos, R. A.; Diaz, G. O.; Gierga, K.; Ghebremedhin, E.; Schultz, C.; Del Turco, D.; Mittelbronn, M.; Auburger, G.; Deller, T.; Braak, H., Damage to the reticulotegmental nucleus of the pons in spinocerebellar ataxia type 1, 2, and 3. Neurology 2004, 63, (7), 1258-63.

14. Rub, U.; Del Turco, D.; Burk, K.; Diaz, G. O.; Auburger, G.; Mittelbronn, M.; Gierga, K.; Ghebremedhin, E.; Schultz, C.; Schols, L.; Bohl, J.; Braak, H.; Deller, T., Extended pathoanatomical studies point to a consistent affection of the thalamus in spinocerebellar ataxia type 2. Neuropathology and applied neurobiology 2005, 31, (2), 127-40.

15. Gierga, K.; Burk, K.; Bauer, M.; Orozco Diaz, G.; Auburger, G.; Schultz, C.; Vuksic, M.; Schols, L.; de Vos, R. A.; Braak, H.; Deller, T.; Rub, U., Involvement of the cranial nerves and their nuclei in spinocerebellar ataxia type 2 (SCA2). Acta neuropathologica 2005, 109, (6), 617-31.

16. Rub, U.; Seidel, K.; Ozerden, I.; Gierga, K.; Brunt, E. R.; Schols, L.; de Vos, R. A.; den Dunnen, W.; Schultz, C.; Auburger, G.; Deller, T., Consistent affection of the central somatosensory system in spinocerebellar ataxia type 2 and type 3 and its significance for clinical symptoms and rehabilitative therapy. Brain Res Rev 2007, 53, (2), 235-49.

17. Rub, U.; Brunt, E. R.; Petrasch-Parwez, E.; Schols, L.; Theegarten, D.; Auburger, G.; Seidel, K.; Schultz, C.; Gierga, K.; Paulson, H.; van Broeckhoven, C.; Deller, T.; de Vos, R. A., Degeneration of ingestion-related brainstem nuclei in spinocerebellar ataxia type 2, 3, 6 and 7. Neuropathology and applied neurobiology 2006, 32, (6), 635-49.

18. Hoche, F.; Seidel, K.; Brunt, E. R.; Auburger, G.; Schols, L.; Burk, K.; de Vos, R. A.; den Dunnen, W.; Bechmann, I.; Egensperger, R.; Van Broeckhoven, C.; Gierga, K.; Deller, T.; Rub, U., Involvement of the auditory brainstem system in spinocerebellar ataxia type 2 (SCA2), type 3 (SCA3) and type 7 (SCA7). Neuropathology and applied neurobiology 2008, 34, (5), 479-91.

19. Lastres-Becker, I.; Rub, U.; Auburger, G., Spinocerebellar ataxia 2 (SCA2). Cerebellum 2008, 7, (2), $115-24$.

20. Hoche, F.; Baliko, L.; den Dunnen, W.; Steinecker, K.; Bartos, L.; Safrany, E.; Auburger, G.; Deller, T.; Korf, H. W.; Klockgether, T.; Rub, U.; Melegh, B., Spinocerebellar ataxia type 2 (SCA2): identification of early brain degeneration in one monozygous twin in the initial disease stage. Cerebellum 2011, 10, (2), 245-53.

21. Scherzed, W.; Brunt, E. R.; Heinsen, H.; de Vos, R. A.; Seidel, K.; Burk, K.; Schols, L.; Auburger, G.; Del Turco, D.; Deller, T.; Korf, H. W.; den Dunnen, W. F.; Rub, U., Pathoanatomy of cerebellar degeneration in spinocerebellar ataxia type 2 (SCA2) and type 3 (SCA3). Cerebellum 2012, 11, (3), 749-60.

22. Rub, U.; Farrag, K.; Seidel, K.; Brunt, E. R.; Heinsen, H.; Burk, K.; Melegh, B.; von Gall, C.; Auburger, G.; Bohl, J.; Korf, H. W.; Hoche, F.; den Dunnen, W., Involvement of the cholinergic basal forebrain nuclei in spinocerebellar ataxia type 2 (SCA2). Neuropathology and applied neurobiology 2013, 39, (6), 634-43. 
23. Rub, U.; Schols, L.; Paulson, H.; Auburger, G.; Kermer, P.; Jen, J. C.; Seidel, K.; Korf, H. W.; Deller, T., Clinical features, neurogenetics and neuropathology of the polyglutamine spinocerebellar ataxias type 1, 2, 3, 6 and 7. Prog Neurobiol 2013, 104, 38-66.

24. Schols, L.; Reimold, M.; Seidel, K.; Globas, C.; Brockmann, K.; Hauser, T. K.; Auburger, G.; Burk, K.; den Dunnen, W.; Reischl, G.; Korf, H. W.; Brunt, E. R.; Rub, U., No parkinsonism in SCA2 and SCA3 despite severe neurodegeneration of the dopaminergic substantia nigra. Brain 2015, 138, (Pt 11), 3316-26.

25. Reetz, K.; Rodriguez-Labrada, R.; Dogan, I.; Mirzazade, S.; Romanzetti, S.; Schulz, J. B.; Cruz-Rivas, E. M.; Alvarez-Cuesta, J. A.; Aguilera Rodriguez, R.; Gonzalez Zaldivar, Y.; Auburger, G.; Velazquez-Perez, L., Brain atrophy measures in preclinical and manifest spinocerebellar ataxia type 2. Ann Clin Transl Neurol 2018, 5, (2), 128-137.

26. Seidel, K.; Siswanto, S.; Fredrich, M.; Bouzrou, M.; den Dunnen, W. F. A.; Ozerden, I.; Korf, H. W.; Melegh, B.; de Vries, J. J.; Brunt, E. R.; Auburger, G.; Rub, U., On the distribution of intranuclear and cytoplasmic aggregates in the brainstem of patients with spinocerebellar ataxia type 2 and 3. Brain Pathol 2017, 27, (3), 345-355.

27. Gispert, S.; Twells, R.; Orozco, G.; Brice, A.; Weber, J.; Heredero, L.; Scheufler, K.; Riley, B.; Allotey, R.; Nothers, C.; et al., Chromosomal assignment of the second locus for autosomal dominant cerebellar ataxia (SCA2) to chromosome 12q23-24.1. Nature genetics 1993, 4, (3), 295-9.

28. Auburger, G.; Diaz, G. O.; Capote, R. F.; Sanchez, S. G.; Perez, M. P.; del Cueto, M. E.; Meneses, M. G.; Farrall, M.; Williamson, R.; Chamberlain, S.; et al., Autosomal dominant ataxia: genetic evidence for locus heterogeneity from a Cuban founder-effect population. Am J Hum Genet 1990, 46, (6), 1163-77.

29. Belal, S.; Cancel, G.; Stevanin, G.; Hentati, F.; Khati, C.; Ben Hamida, C.; Auburger, G.; Agid, Y.; Ben Hamida, M.; Brice, A., Clinical and genetic analysis of a Tunisian family with autosomal dominant cerebellar ataxia type 1 linked to the SCA2 locus. Neurology 1994, 44, (8), 1423-6.

30. Hernandez, A.; Magarino, C.; Gispert, S.; Santos, N.; Lunkes, A.; Orozco, G.; Heredero, L.; Beckmann, J.; Auburger, G., Genetic mapping of the spinocerebellar ataxia 2 (SCA2) locus on chromosome 12q23-q24.1. Genomics 1995, 25, (2), 433-5.

31. Schols, L.; Gispert, S.; Vorgerd, M.; Menezes Vieira-Saecker, A. M.; Blanke, P.; Auburger, G.; Amoiridis, G.; Meves, S.; Epplen, J. T.; Przuntek, H.; Pulst, S. M.; Riess, O., Spinocerebellar ataxia type 2. Genotype and phenotype in German kindreds. Arch Neurol 1997, 54, (9), 1073-80.

32. Riess, O.; Laccone, F. A.; Gispert, S.; Schols, L.; Zuhlke, C.; Vieira-Saecker, A. M.; Herlt, S.; Wessel, K.; Epplen, J. T.; Weber, B. H.; Kreuz, F.; Chahrokh-Zadeh, S.; Meindl, A.; Lunkes, A.; Aguiar, J.; Macek, M., Jr.; Krebsova, A.; Macek, M., Sr.; Burk, K.; Tinschert, S.; Schreyer, I.; Pulst, S. M.; Auburger, G., SCA2 trinucleotide expansion in German SCA patients. Neurogenetics 1997, 1, (1), 59-64.

33. Almaguer-Mederos, L. E.; Aguilera Rodriguez, R.; Gonzalez Zaldivar, Y.; Almaguer Gotay, D.; Cuello Almarales, D.; Laffita Mesa, J.; Vazquez Mojena, Y.; Zayas Feria, P.; Auburger, G.; Gispert, S.; Velasquez Perez, L., Estimation of survival in spinocerebellar ataxia type 2 Cuban patients. Clin Genet 2013, 83, (3), 293-4.

34. Almaguer-Mederos, L. E.; Falcon, N. S.; Almira, Y. R.; Zaldivar, Y. G.; Almarales, D. C.; Gongora, E. M.; Herrera, M. P.; Batallan, K. E.; Arminan, R. R.; Manresa, M. V.; Cruz, G. S.; Laffita-Mesa, J.; Cyuz, T. M.; Chang, V.; Auburger, G.; Gispert, S.; Perez, L. V., Estimation of the age at onset in spinocerebellar ataxia type 2 Cuban patients by survival analysis. Clin Genet 2010, 78, (2), 169-74. 
46.
35. Elden, A. C.; Kim, H. J.; Hart, M. P.; Chen-Plotkin, A. S.; Johnson, B. S.; Fang, X.; Armakola, M.; Geser, F.; Greene, R.; Lu, M. M.; Padmanabhan, A.; Clay-Falcone, D.; McCluskey, L.; Elman, L.; Juhr, D.; Gruber, P. J.; Rub, U.; Auburger, G.; Trojanowski, J. Q.; Lee, V. M.; Van Deerlin, V. M.; Bonini, N. M.; Gitler, A. D., Ataxin-2 intermediate-length polyglutamine expansions are associated with increased risk for ALS. Nature 2010, 466, (7310), 1069-75.

36. Lee, T.; Li, Y. R.; Ingre, C.; Weber, M.; Grehl, T.; Gredal, O.; de Carvalho, M.; Meyer, T.; Tysnes, O. B.; Auburger, G.; Gispert, S.; Bonini, N. M.; Andersen, P. M.; Gitler, A. D., Ataxin-2 intermediate-length polyglutamine expansions in European ALS patients. Human molecular genetics 2011, 20, (9), 1697-700.

37. Gispert, S.; Kurz, A.; Waibel, S.; Bauer, P.; Liepelt, I.; Geisen, C.; Gitler, A. D.; Becker, T.; Weber, M.; Berg, D.; Andersen, P. M.; Kruger, R.; Riess, O.; Ludolph, A. C.; Auburger, G., The modulation of Amyotrophic Lateral Sclerosis risk by ataxin-2 intermediate polyglutamine expansions is a specific effect. Neurobiol Dis 2012, 45, (1), 356-61.

38. Lahut, S.; Omur, O.; Uyan, O.; Agim, Z. S.; Ozoguz, A.; Parman, Y.; Deymeer, F.; Oflazer, P.; Koc, F.; Ozcelik, H.; Auburger, G.; Basak, A. N., ATXN2 and its neighbouring gene SH2B3 are associated with increased ALS risk in the Turkish population. PLoS One 2012, 7, (8), e42956.

39. Velazquez-Perez, L.; Rodriguez-Labrada, R.; Torres-Vega, R.; Montero, J. M.; Vazquez-Mojena, Y.; Auburger, G.; Ziemann, U., Central motor conduction time as prodromal biomarker in spinocerebellar ataxia type 2. Movement disorders : official journal of the Movement Disorder Society 2016, 31, (4), 603-4.

40. Velazquez-Perez, L.; Rodriguez-Labrada, R.; Torres-Vega, R.; Medrano Montero, J.; Vazquez-Mojena, Y.; Auburger, G.; Ziemann, U., Abnormal corticospinal tract function and motor cortex excitability in non-ataxic SCA2 mutation carriers: A TMS study. Clin Neurophysiol 2016, 127, (8), 2713-2719.

41. Velazquez-Perez, L.; Tunnerhoff, J.; Rodriguez-Labrada, R.; Torres-Vega, R.; Belardinelli, P.; Medrano-Montero, J.; Pena-Acosta, A.; Canales-Ochoa, N.; Vazquez-Mojena, Y.; Gonzalez-Zaldivar, Y.; Auburger, G.; Ziemann, U., Corticomuscular Coherence: a Novel Tool to Assess the Pyramidal Tract Dysfunction in Spinocerebellar Ataxia Type 2. Cerebellum 2017, 16, (2), 602-606.

42. Becker, L. A.; Huang, B.; Bieri, G.; Ma, R.; Knowles, D. A.; Jafar-Nejad, P.; Messing, J.; Kim, H. J.; Soriano, A.; Auburger, G.; Pulst, S. M.; Taylor, J. P.; Rigo, F.; Gitler, A. D., Therapeutic reduction of ataxin-2 extends lifespan and reduces pathology in TDP-43 mice. Nature 2017, 544, (7650), 367-371.

43. Velazquez-Perez, L.; Rodriguez-Labrada, R.; Torres-Vega, R.; Ortega-Sanchez, R.; Medrano-Montero, J.; Gonzalez-Pina, R.; Vazquez-Mojena, Y.; Auburger, G.; Ziemann, U., Progression of corticospinal tract dysfunction in pre-ataxic spinocerebellar ataxia type 2: A two-years follow-up TMS study. Clin Neurophysiol 2018, 129, (5), 895-900.

44. Velazquez-Perez, L.; Tunnerhoff, J.; Rodriguez-Labrada, R.; Torres-Vega, R.; Ruiz-Gonzalez, Y.; Belardinelli, P.; Medrano-Montero, J.; Canales-Ochoa, N.; Gonzalez-Zaldivar, Y.; Vazquez-Mojena, Y.; Auburger, G.; Ziemann, U., Early corticospinal tract damage in prodromal SCA2 revealed by EEG-EMG and EMG-EMG coherence. Clin Neurophysiol 2017, 128, (12), 2493-2502.

45. Rubino, E.; Mancini, C.; Boschi, S.; Ferrero, P.; Ferrone, M.; Bianca, S.; Zucca, M.; Orsi, L.; Pinessi, L.; Govone, F.; Vacca, A.; Gai, A.; Giordana, M. T.; Brusco, A.; Rainero, I., ATXN2 intermediate repeat expansions influence the clinical phenotype in frontotemporal dementia. Neurobiol Aging 2019, 73, 231 e7-231 e9. Van Langenhove, T.; van der Zee, J.; Engelborghs, S.; Vandenberghe, R.; Santens, P.; Van den Broeck, M.; Mattheijssens, M.; Peeters, K.; Nuytten, D.; Cras, P.; De Deyn, P. P.; De Jonghe, P.; Cruts, M.; Van 
Broeckhoven, C., Ataxin-2 polyQ expansions in FTLD-ALS spectrum disorders in Flanders-Belgian cohorts. Neurobiol Aging 2012, 33, (5), 1004 e17-20.

47. Ross, O. A.; Rutherford, N. J.; Baker, M.; Soto-Ortolaza, A. I.; Carrasquillo, M. M.; DeJesus-Hernandez, M.; Adamson, J.; Li, M.; Volkening, K.; Finger, E.; Seeley, W. W.; Hatanpaa, K. J.; Lomen-Hoerth, C.; Kertesz, A.; Bigio, E. H.; Lippa, C.; Woodruff, B. K.; Knopman, D. S.; White, C. L., 3rd; Van Gerpen, J. A.; Meschia, J. F.; Mackenzie, I. R.; Boylan, K.; Boeve, B. F.; Miller, B. L.; Strong, M. J.; Uitti, R. J.; Younkin, S. G.; Graff-Radford, N. R.; Petersen, R. C.; Wszolek, Z. K.; Dickson, D. W.; Rademakers, R., Ataxin-2 repeat-length variation and neurodegeneration. Human molecular genetics 2011, 20, (16), 3207-12.

48. Klockgether, T.; Wullner, U.; Spauschus, A.; Evert, B., The molecular biology of the autosomal-dominant cerebellar ataxias. Mov Disord 2000, 15, (4), 604-12.

49. Orr, H. T., Beyond the Qs in the polyglutamine diseases. Genes \& development 2001, 15, (8), 925-32.

50. Halbach, M. V.; Stehning, T.; Damrath, E.; Jendrach, M.; Sen, N. E.; Basak, A. N.; Auburger, G., Both ubiquitin ligases FBXW8 and PARK2 are sequestrated into insolubility by ATXN2 PolyQ expansions, but only FBXW8 expression is dysregulated. PLoS One 2015, 10, (3), e0121089.

51. Halbach, M. V.; Gispert, S.; Stehning, T.; Damrath, E.; Walter, M.; Auburger, G., Atxn2 Knockout and CAG42-Knock-in Cerebellum Shows Similarly Dysregulated Expression in Calcium Homeostasis Pathway. Cerebellum 2017, 16, (1), 68-81.

52. Almaguer-Mederos, L. E.; Mesa, J. M. L.; Gonzalez-Zaldivar, Y.; Almaguer-Gotay, D.; Cuello-Almarales, D.; Aguilera-Rodriguez, R.; Falcon, N. S.; Gispert, S.; Auburger, G.; Velazquez-Perez, L., Factors associated with ATXN2 CAG/CAA repeat intergenerational instability in Spinocerebellar ataxia type 2. Clin Genet 2018, 94, (3-4), 346-350.

53. Sen, N. E.; Canet-Pons, J.; Halbach, M. V.; Arsovic, A.; Pilatus, U.; Chae, W. H.; Kaya, Z. E.; Seidel, K.; Rollmann, E.; Mittelbronn, M.; Meierhofer, D.; De Zeeuw, C. I.; Bosman, L. W. J.; Gispert, S.; Auburger, G., Generation of an Atxn2-CAG100 knock-in mouse reveals N-acetylaspartate production deficit due to early Nat81 dysregulation. Neurobiol Dis 2019, 132, 104559.

54. Damrath, E.; Heck, M. V.; Gispert, S.; Azizov, M.; Nowock, J.; Seifried, C.; Rub, U.; Walter, M.; Auburger, G., ATXN2-CAG42 sequesters PABPC1 into insolubility and induces FBXW8 in cerebellum of old ataxic knock-in mice. PLoS Genet 2012, 8, (8), e1002920.

55. Nussbaum, R.; Auburger, G., Neurodegeneration in the polyglutamine diseases: Act 1, Scene 1. Nat Neurosci 2000, 3, (2), 103-4.

56. Sen, N. E.; Arsovic, A.; Meierhofer, D.; Brodesser, S.; Oberschmidt, C.; Canet-Pons, J.; Kaya, Z. E.; Halbach, M. V.; Gispert, S.; Sandhoff, K.; Auburger, G., In Human and Mouse Spino-Cerebellar Tissue, Ataxin-2 Expansion Affects Ceramide-Sphingomyelin Metabolism. Int J Mol Sci 2019, 20, (23).

57. Caughey, B.; Lansbury, P. T., Protofibrils, pores, fibrils, and neurodegeneration: separating the responsible protein aggregates from the innocent bystanders. Annual review of neuroscience 2003, 26, 267-98.

58. Perutz, M. F.; Johnson, T.; Suzuki, M.; Finch, J. T., Glutamine repeats as polar zippers: their possible role in inherited neurodegenerative diseases. Proceedings of the National Academy of Sciences of the United States of America 1994, 91, (12), 5355-8.

59. Zhang, X.; Abels, E. R.; Redzic, J. S.; Margulis, J.; Finkbeiner, S.; Breakefield, X. O., Potential Transfer of Polyglutamine and CAG-Repeat RNA in Extracellular Vesicles in Huntington's Disease: Background and Evaluation in Cell Culture. Cell Mol Neurobiol 2016, 36, (3), 459-70. 
$706 \quad 60$
60. Olejniczak, M.; Urbanek, M. O.; Krzyzosiak, W. J., The role of the immune system in triplet repeat expansion diseases. Mediators Inflamm 2015, 2015, 873860.

61. Canet-Pons, J.; Sen, N. E.; Arsovic, A.; Almaguer-Mederos, L.; Halbach, M. V.; Key, J.; Döring, C.; Kerksiek, A.; Picchiarelli, G.; Cassel, R.; René, F.; Dieterlé, S.; Hein-Fuchs, N.; König, R.; Dupuis, L.; Lütjohann, D.; Gispert, S.; Auburger, G., Atxn2-CAG100-KnockIn mouse spinal cord shows progressive TDP43 pathology associated with cholesterol biosynthesis suppression. https://www.biorxiv.org/content/10.1101/838177v1.

62. Sakahira, H.; Breuer, P.; Hayer-Hartl, M. K.; Hartl, F. U., Molecular chaperones as modulators of polyglutamine protein aggregation and toxicity. Proceedings of the National Academy of Sciences of the United States of America 2002, 99 Suppl 4, 16412-8.

63. Cortes, C. J.; La Spada, A. R., Autophagy in polyglutamine disease: Imposing order on disorder or contributing to the chaos? Mol Cell Neurosci 2015, 66, (Pt A), 53-61.

64. Cummings, C. J.; Sun, Y.; Opal, P.; Antalffy, B.; Mestril, R.; Orr, H. T.; Dillmann, W. H.; Zoghbi, H. Y., Over-expression of inducible HSP70 chaperone suppresses neuropathology and improves motor function in SCA1 mice. Human molecular genetics 2001, 10, (14), 1511-8.

65. Saudou, F.; Finkbeiner, S.; Devys, D.; Greenberg, M. E., Huntingtin acts in the nucleus to induce apoptosis but death does not correlate with the formation of intranuclear inclusions. Cell 1998, 95, (1), 55-66.

66. Paulson, H. L.; Shakkottai, V. G.; Clark, H. B.; Orr, H. T., Polyglutamine spinocerebellar ataxias - from genes to potential treatments. Nat Rev Neurosci 2017, 18, (10), 613-626.

67. Farg, M. A.; Soo, K. Y.; Warraich, S. T.; Sundaramoorthy, V.; Blair, I. P.; Atkin, J. D., Ataxin-2 interacts with FUS and intermediate-length polyglutamine expansions enhance FUS-related pathology in amyotrophic lateral sclerosis. Human molecular genetics 2013, 22, (4), 717-28.

68. Huynh, D. P.; Del Bigio, M. R.; Ho, D. H.; Pulst, S. M., Expression of ataxin-2 in brains from normal individuals and patients with Alzheimer's disease and spinocerebellar ataxia 2. Annals of neurology $1999,45,(2), 232-41$.

69. van de Loo, S.; Eich, F.; Nonis, D.; Auburger, G.; Nowock, J., Ataxin-2 associates with rough endoplasmic reticulum. Exp Neurol 2009, 215, (1), 110-8.

70. Fittschen, M.; Lastres-Becker, I.; Halbach, M. V.; Damrath, E.; Gispert, S.; Azizov, M.; Walter, M.; Muller, S.; Auburger, G., Genetic ablation of ataxin-2 increases several global translation factors in their transcript abundance but decreases translation rate. Neurogenetics 2015, 16, (3), 181-92.

71. Del Castillo, U.; Gnazzo, M. M.; Sorensen Turpin, C. G.; Nguyen, K. C. Q.; Semaya, E.; Lam, Y.; de Cruz, M. A.; Bembenek, J. N.; Hall, D. H.; Riggs, B.; Gelfand, V. I.; Skop, A. R., Conserved role for Ataxin-2 in mediating endoplasmic reticulum dynamics. Traffic 2019, 20, (6), 436-447.

72. Nonis, D.; Schmidt, M. H. H.; van de Loo, S.; Eich, F.; Dikic, I.; Nowock, J.; Auburger, G., Ataxin-2 associates with the endocytosis complex and affects EGF receptor trafficking. Cell Signal 2008, 20, (10), 1725-39.

73. Drost, J.; Nonis, D.; Eich, F.; Leske, O.; Damrath, E.; Brunt, E. R.; Lastres-Becker, I.; Heumann, R.; Nowock, J.; Auburger, G., Ataxin-2 modulates the levels of Grb2 and SRC but not ras signaling. J Mol Neurosci 2013, 51, (1), 68-81. Ataxin-2 interacts with the DEAD/H-box RNA helicase DDX6 and interferes with P-bodies and stress granules. Molecular biology of the cell 2007, 18, (4), 1385-96. 
74975
75. Swisher, K. D.; Parker, R., Localization to, and effects of Pbp1, Pbp4, Lsm12, Dhh1, and Pab1 on stress granules in Saccharomyces cerevisiae. PLoS One 2010, 5, (4), e10006.

76. Satterfield, T. F.; Pallanck, L. J., Ataxin-2 and its Drosophila homolog, ATX2, physically assemble with polyribosomes. Human molecular genetics 2006, 15, (16), 2523-32.

77. Yokoshi, M.; Li, Q.; Yamamoto, M.; Okada, H.; Suzuki, Y.; Kawahara, Y., Direct binding of Ataxin-2 to distinct elements in 3' UTRs promotes mRNA stability and protein expression. Mol Cell 2014, 55, (2), 186-98.

78. Jimenez-Lopez, D.; Guzman, P., Insights into the evolution and domain structure of Ataxin-2 proteins across eukaryotes. BMC Res Notes 2014, 7, 453.

79. Satterfield, T. F.; Jackson, S. M.; Pallanck, L. J., A Drosophila homolog of the polyglutamine disease gene SCA2 is a dosage-sensitive regulator of actin filament formation. Genetics 2002, 162, (4), 1687-702.

80. Ralser, M.; Albrecht, M.; Nonhoff, U.; Lengauer, T.; Lehrach, H.; Krobitsch, S., An integrative approach to gain insights into the cellular function of human ataxin-2. Journal of molecular biology 2005, 346, (1), 203-14.

81. Shibata, H.; Huynh, D. P.; Pulst, S. M., A novel protein with RNA-binding motifs interacts with ataxin-2. Human molecular genetics 2000, 9, (9), 1303-13.

82. Ralser, M.; Nonhoff, U.; Albrecht, M.; Lengauer, T.; Wanker, E. E.; Lehrach, H.; Krobitsch, S., Ataxin-2 and huntingtin interact with endophilin-A complexes to function in plastin-associated pathways. Human molecular genetics 2005, 14, (19), 2893-909.

83. Lastres-Becker, I.; Nonis, D.; Nowock, J.; Auburger, G., New alternative splicing variants of the ATXN2 transcript. Neurological Research and Practice 2019, 2019, (1).

84. Lim, J.; Hao, T.; Shaw, C.; Patel, A. J.; Szabo, G.; Rual, J. F.; Fisk, C. J.; Li, N.; Smolyar, A.; Hill, D. E.; Barabasi, A. L.; Vidal, M.; Zoghbi, H. Y., A protein-protein interaction network for human inherited ataxias and disorders of Purkinje cell degeneration. Cell 2006, 125, (4), 801-14.

85. Rual, J. F.; Hirozane-Kishikawa, T.; Hao, T.; Bertin, N.; Li, S.; Dricot, A.; Li, N.; Rosenberg, J.; Lamesch, P.; Vidalain, P. O.; Clingingsmith, T. R.; Hartley, J. L.; Esposito, D.; Cheo, D.; Moore, T.; Simmons, B.; Sequerra, R.; Bosak, S.; Doucette-Stamm, L.; Le Peuch, C.; Vandenhaute, J.; Cusick, M. E.; Albala, J. S.; Hill, D. E.; Vidal, M., Human ORFeome version 1.1: a platform for reverse proteomics. Genome research 2004, 14, (10B), 2128-35.

86. Sjoblom, B.; Salmazo, A.; Djinovic-Carugo, K., Alpha-actinin structure and regulation. Cell Mol Life Sci 2008, 65, (17), 2688-701.

87. Kemp, J. P., Jr.; Brieher, W. M., The actin filament bundling protein alpha-actinin-4 actually suppresses actin stress fibers by permitting actin turnover. The Journal of biological chemistry 2018, 293, (37), 14520-14533.

88. Kovac, B.; Makela, T. P.; Vallenius, T., Increased alpha-actinin-1 destabilizes E-cadherin-based adhesions and associates with poor prognosis in basal-like breast cancer. PLoS One 2018, 13, (5), e0196986.

89. Senger, F.; Pitaval, A.; Ennomani, H.; Kurzawa, L.; Blanchoin, L.; Thery, M., Spatial integration of mechanical forces by alpha-actinin establishes actin network symmetry. J Cell Sci 2019, 132, (22).

90. Fu, C.; Xu, J.; Cheng, W.; Rojas, T.; Chin, A. C.; Snowman, A. M.; Harraz, M. M.; Snyder, S. H., Neuronal migration is mediated by inositol hexakisphosphate kinase 1 via alpha-actinin and focal adhesion kinase. Proceedings of the National Academy of Sciences of the United States of America 2017, 114, (8), 2036-2041. 
91. Ehrlicher, A. J.; Krishnan, R.; Guo, M.; Bidan, C. M.; Weitz, D. A.; Pollak, M. R., Alpha-actinin binding kinetics modulate cellular dynamics and force generation. Proceedings of the National Academy of Sciences of the United States of America 2015, 112, (21), 6619-24.

92. Falzone, T. T.; Lenz, M.; Kovar, D. R.; Gardel, M. L., Assembly kinetics determine the architecture of alpha-actinin crosslinked F-actin networks. Nat Commun 2012, 3, 861.

93. Matt, L.; Kim, K.; Hergarden, A. C.; Patriarchi, T.; Malik, Z. A.; Park, D. K.; Chowdhury, D.; Buonarati, O. R.; Henderson, P. B.; Gokcek Sarac, C.; Zhang, Y.; Mohapatra, D.; Horne, M. C.; Ames, J. B.; Hell, J. W., alpha-Actinin Anchors PSD-95 at Postsynaptic Sites. Neuron 2018, 97, (5), 1094-1109 e9.

94. Khurana, S.; Chakraborty, S.; Zhao, X.; Liu, Y.; Guan, D.; Lam, M.; Huang, W.; Yang, S.; Kao, H. Y., Identification of a novel LXXLL motif in alpha-actinin 4-spliced isoform that is critical for its interaction with estrogen receptor alpha and co-activators. The Journal of biological chemistry 2012, 287, (42), 35418-29.

95. Otey, C. A.; Carpen, O., Alpha-actinin revisited: a fresh look at an old player. Cell motility and the cytoskeleton 2004, 58, (2), 104-11.

96. Meacci, G.; Wolfenson, H.; Liu, S.; Stachowiak, M. R.; Iskratsch, T.; Mathur, A.; Ghassemi, S.; Gauthier, N.; Tabdanov, E.; Lohner, J.; Gondarenko, A.; Chander, A. C.; Roca-Cusachs, P.; O'Shaughnessy, B.; Hone, J.; Sheetz, M. P., alpha-Actinin links extracellular matrix rigidity-sensing contractile units with periodic cell-edge retractions. Molecular biology of the cell 2016, 27, (22), 3471-3479.

97. Furutani, Y.; Matsuno, H.; Kawasaki, M.; Sasaki, T.; Mori, K.; Yoshihara, Y., Interaction between telencephalin and ERM family proteins mediates dendritic filopodia formation. The Journal of neuroscience : the official journal of the Society for Neuroscience 2007, 27, (33), 8866-76.

98. Choi, C. K.; Vicente-Manzanares, M.; Zareno, J.; Whitmore, L. A.; Mogilner, A.; Horwitz, A. R., Actin and alpha-actinin orchestrate the assembly and maturation of nascent adhesions in a myosin II motor-independent manner. Nat Cell Biol 2008, 10, (9), 1039-50.

99. Milanini, J.; Fayad, R.; Partisani, M.; Lecine, P.; Borg, J. P.; Franco, M.; Luton, F., EFA6 proteins regulate lumen formation through alpha-actinin 1. J Cell Sci 2018, 131, (3).

100. Li, D.; Shao, L.; Chen, B. C.; Zhang, X.; Zhang, M.; Moses, B.; Milkie, D. E.; Beach, J. R.; Hammer, J. A., 3rd; Pasham, M.; Kirchhausen, T.; Baird, M. A.; Davidson, M. W.; Xu, P.; Betzig, E., ADVANCED IMAGING. Extended-resolution structured illumination imaging of endocytic and cytoskeletal dynamics. Science 2015, 349, (6251), aab3500.

101. Geiger, B.; Singer, S. J., The participation of alpha-actinin in the capping of cell membrane components. Cell 1979, 16, (1), 213-22.

102. Vassilopoulos, S.; Gentil, C.; Laine, J.; Buclez, P. O.; Franck, A.; Ferry, A.; Precigout, G.; Roth, R.; Heuser, J. E.; Brodsky, F. M.; Garcia, L.; Bonne, G.; Voit, T.; Pietri-Rouxel, F.; Bitoun, M., Actin scaffolding by clathrin heavy chain is required for skeletal muscle sarcomere organization. The Journal of cell biology 2014, 205, (3), 377-93.

103. Menon, M.; Askinazi, O. L.; Schafer, D. A., Dynamin2 organizes lamellipodial actin networks to orchestrate lamellar actomyosin. PLoS One 2014, 9, (4), e94330.

104. Piirainen, H.; Taura, J.; Kursula, P.; Ciruela, F.; Jaakola, V. P., Calcium modulates calmodulin/alpha-actinin 1 interaction with and agonist-dependent internalization of the adenosine A2A receptor. Biochim Biophys Acta Mol Cell Res 2017, 1864, (4), 674-686.

105. Hall, D. D.; Dai, S.; Tseng, P. Y.; Malik, Z.; Nguyen, M.; Matt, L.; Schnizler, K.; Shephard, A.; Mohapatra, D. P.; Tsuruta, F.; Dolmetsch, R. E.; Christel, C. J.; Lee, A.; Burette, A.; Weinberg, R. J.; Hell, 
J. W., Competition between alpha-actinin and $\mathrm{Ca}(2)(+)$-calmodulin controls surface retention of the L-type $\mathrm{Ca}(2)(+)$ channel Ca(V)1.2. Neuron 2013, 78, (3), 483-97.

106. Stradal, T.; Kranewitter, W.; Winder, S. J.; Gimona, M., CH domains revisited. FEBS letters 1998, 431, (2), 134-7.

107. Djinovic-Carugo, K.; Gautel, M.; Ylanne, J.; Young, P., The spectrin repeat: a structural platform for

108. Liao, Q.; Li, R.; Zhou, R.; Pan, Z.; Xu, L.; Ding, Y.; Zhao, L., LIM kinase 1 interacts with myosin-9 and

109. Sobue, K., Actin-based cytoskeleton in growth cone activity. Neurosci Res 1993, 18, (2), 91-102.

110. Sharma, P.; Shathasivam, T.; Ignatchenko, V.; Kislinger, T.; Gramolini, A. O., Identification of an FHL1 protein complex containing ACTN1, ACTN4, and PDLIM1 using affinity purifications and MS-based protein-protein interaction analysis. Mol Biosyst 2011, 7, (4), 1185-96.

111. Sobue, K.; Kanda, K., Alpha-actinins, calspectin (brain spectrin or fodrin), and actin participate in 112. Shao, H.; Wu, C.; Wells, A., Phosphorylation of alpha-actinin 4 upon epidermal growth factor 113. Xaymardan, M.; Cimini, M.; Fazel, S.; Weisel, R. D.; Lu, W. Y.; Martin, U.; Harvey, R. P.; Li, R. K., c-Kit exposure regulates its interaction with actin. The Journal of biological chemistry 2010, 285, (4), 2591-600.

function is necessary for in vitro myogenic differentiation of bone marrow hematopoietic cells. Stem Cells 2009, 27, (8), 1911-20.

114. Lockhart, S. T.; Mead, J. N.; Pisano, J. M.; Slonimsky, J. D.; Birren, S. J., Nerve growth factor collaborates with myocyte-derived factors to promote development of presynaptic sites in cultured sympathetic neurons. J Neurobiol 2000, 42, (4), 460-76.

115. Manova, K.; Bachvarova, R. F.; Huang, E. J.; Sanchez, S.; Pronovost, S. M.; Velazquez, E.; McGuire, B.; Besmer, P., c-kit receptor and ligand expression in postnatal development of the mouse cerebellum suggests a function for c-kit in inhibitory interneurons. The Journal of neuroscience : the official journal of the Society for Neuroscience 1992, 12, (12), 4663-76.

116. Villalobo, A.; Gonzalez-Munoz, M.; Berchtold, M. W., Proteins with calmodulin-like domains: structures and functional roles. Cell Mol Life Sci 2019, 76, (12), 2299-2328.

117. Delanote, V.; Vandekerckhove, J.; Gettemans, J., Plastins: versatile modulators of actin organization in (patho)physiological cellular processes. Acta pharmacologica Sinica 2005, 26, (7), 769-79.

118. Shams, H.; Golji, J.; Garakani, K.; Mofrad, M. R., Dynamic Regulation of alpha-Actinin's Calponin Homology Domains on F-Actin. Biophys J 2016, 110, (6), 1444-55.

119. Christensen, J. R.; Homa, K. E.; Morganthaler, A. N.; Brown, R. R.; Suarez, C.; Harker, A. J.; O'Connell, M. E.; Kovar, D. R., Cooperation between tropomyosin and alpha-actinin inhibits fimbrin association with actin filament networks in fission yeast. Elife 2019, 8.

120. Laporte, D.; Ojkic, N.; Vavylonis, D.; Wu, J. Q., alpha-Actinin and fimbrin cooperate with myosin II to organize actomyosin bundles during contractile-ring assembly. Molecular biology of the cell 2012, 23, (16), 3094-110.

121. Qualmann, B.; Kessels, M. M.; Kelly, R. B., Molecular links between endocytosis and the actin cytoskeleton. The Journal of cell biology 2000, 150, (5), F111-6.

Yarar, D.; Waterman-Storer, C. M.; Schmid, S. L., A dynamic actin cytoskeleton functions at multiple stages of clathrin-mediated endocytosis. Molecular biology of the cell 2005, 16, (2), 964-75. 
123. Yarar, D.; Waterman-Storer, C. M.; Schmid, S. L., SNX9 couples actin assembly to phosphoinositide signals and is required for membrane remodeling during endocytosis. Developmental cell 2007, 13, (1), 43-56.

124. Lastres-Becker, I.; Nonis, D.; Eich, F.; Klinkenberg, M.; Gorospe, M.; Kotter, P.; Klein, F. A.; Kedersha, N.; Auburger, G., Mammalian ataxin-2 modulates translation control at the pre-initiation complex via PI3K/mTOR and is induced by starvation. Biochim Biophys Acta 2016, 1862, (9), 1558-69.

125. Auburger, G.; Sen, N. E.; Meierhofer, D.; Basak, A. N.; Gitler, A. D., Efficient Prevention of Neurodegenerative Diseases by Depletion of Starvation Response Factor Ataxin-2. Trends Neurosci 2017, 40, (8), 507-516.

126. Bar, D. Z.; Charar, C.; Dorfman, J.; Yadid, T.; Tafforeau, L.; Lafontaine, D. L.; Gruenbaum, Y., Cell size and fat content of dietary-restricted Caenorhabditis elegans are regulated by ATX-2, an mTOR repressor. Proceedings of the National Academy of Sciences of the United States of America 2016, 113, (32), E4620-9.

127. DeMille, D.; Badal, B. D.; Evans, J. B.; Mathis, A. D.; Anderson, J. F.; Grose, J. H., PAS kinase is activated by direct SNF1-dependent phosphorylation and mediates inhibition of TORC1 through the phosphorylation and activation of Pbp1. Molecular biology of the cell 2015, 26, (3), 569-82.

128. Yang, Y. S.; Kato, M.; Wu, X.; Litsios, A.; Sutter, B. M.; Wang, Y.; Hsu, C. H.; Wood, N. E.; Lemoff, A.; Mirzaei, H.; Heinemann, M.; Tu, B. P., Yeast Ataxin-2 Forms an Intracellular Condensate Required for the Inhibition of TORC1 Signaling during Respiratory Growth. Cell 2019, 177, (3), 697-710 e17.

129. Kato, M.; Yang, Y. S.; Sutter, B. M.; Wang, Y.; McKnight, S. L.; Tu, B. P., Redox State Controls Phase Separation of the Yeast Ataxin-2 Protein via Reversible Oxidation of Its Methionine-Rich Low-Complexity Domain. Cell 2019, 177, (3), 711-721 e8.

130. Watanabe, S.; Mamer, L. E.; Raychaudhuri, S.; Luvsanjav, D.; Eisen, J.; Trimbuch, T.; Sohl-Kielczynski, B.; Fenske, P.; Milosevic, I.; Rosenmund, C.; Jorgensen, E. M., Synaptojanin and Endophilin Mediate Neck Formation during Ultrafast Endocytosis. Neuron 2018, 98, (6), 1184-1197 e6.

131. Boucrot, E.; Ferreira, A. P.; Almeida-Souza, L.; Debard, S.; Vallis, Y.; Howard, G.; Bertot, L.; Sauvonnet, N.; McMahon, H. T., Endophilin marks and controls a clathrin-independent endocytic pathway. Nature 2015, 517, (7535), 460-5.

132. Renard, H. F.; Simunovic, M.; Lemiere, J.; Boucrot, E.; Garcia-Castillo, M. D.; Arumugam, S.; Chambon, V.; Lamaze, C.; Wunder, C.; Kenworthy, A. K.; Schmidt, A. A.; McMahon, H. T.; Sykes, C.; Bassereau, P.; Johannes, L., Endophilin-A2 functions in membrane scission in clathrin-independent endocytosis. Nature 2015, 517, (7535), 493-6.

134. Schook, W.; Puszkin, S.; Bloom, W.; Ores, C.; Kochwa, S., Mechanochemical properties of brain clathrin: interactions with actin and alpha-actinin and polymerization into basketlike structures or filaments. Proceedings of the National Academy of Sciences of the United States of America 1979, 76, (1), 116-20.

135. Goode, B. L.; Eskin, J. A.; Wendland, B., Actin and endocytosis in budding yeast. Genetics 2015, 199, (2), 315-58.

136. Gimona, M.; Djinovic-Carugo, K.; Kranewitter, W. J.; Winder, S. J., Functional plasticity of CH domains. FEBS letters 2002, 513, (1), 98-106.

Sjoblom, B.; Ylanne, J.; Djinovic-Carugo, K., Novel structural insights into F-actin-binding and novel functions of calponin homology domains. Curr Opin Struct Biol 2008, 18, (6), 702-8. 
138. Scoles, D. R.; Pflieger, L. T.; Thai, K. K.; Hansen, S. T.; Dansithong, W.; Pulst, S. M., ETS1 regulates the expression of ATXN2. Human molecular genetics 2012, 21, (23), 5048-65.

139. Huynh, D. P.; Figueroa, K.; Hoang, N.; Pulst, S. M., Nuclear localization or inclusion body formation of ataxin-2 are not necessary for SCA2 pathogenesis in mouse or human. Nature genetics 2000, 26, (1), 44-50.

140. van den Bos, M. A. J.; Geevasinga, N.; Higashihara, M.; Menon, P.; Vucic, S., Pathophysiology and Diagnosis of ALS: Insights from Advances in Neurophysiological Techniques. Int J Mol Sci 2019, 20, (11).

141. Nuriya, M.; Oh, S.; Huganir, R. L., Phosphorylation-dependent interactions of alpha-Actinin-1/IQGAP1 with the AMPA receptor subunit GluR4. Journal of neurochemistry 2005, 95, (2), 544-52.

142. Buonarati, O. R.; Hammes, E. A.; Watson, J. F.; Greger, I. H.; Hell, J. W., Mechanisms of postsynaptic localization of AMPA-type glutamate receptors and their regulation during long-term potentiation. Sci Signal 2019, 12, (562).

143. Cabello, N.; Remelli, R.; Canela, L.; Soriguera, A.; Mallol, J.; Canela, E. I.; Robbins, M. J.; Lluis, C.; Franco, R.; McIlhinney, R. A.; Ciruela, F., Actin-binding protein alpha-actinin-1 interacts with the metabotropic glutamate receptor type $5 \mathrm{~b}$ and modulates the cell surface expression and function of the receptor. The Journal of biological chemistry 2007, 282, (16), 12143-53.

144. Dhavan, R.; Greer, P. L.; Morabito, M. A.; Orlando, L. R.; Tsai, L. H., The cyclin-dependent kinase 5 activators p35 and p39 interact with the alpha-subunit of Ca2+/calmodulin-dependent protein kinase II and alpha-actinin-1 in a calcium-dependent manner. The Journal of neuroscience : the official journal of the Society for Neuroscience 2002, 22, (18), 7879-91.

145. Borovac, J.; Bosch, M.; Okamoto, K., Regulation of actin dynamics during structural plasticity of dendritic spines: Signaling messengers and actin-binding proteins. Mol Cell Neurosci 2018, 91, 122-130.

146. Penny, C. J.; Gold, M. G., Mechanisms for localising calcineurin and CaMKII in dendritic spines. Cell Signal 2018, 49, 46-58.

147. Kalinowska, M.; Chavez, A. E.; Lutzu, S.; Castillo, P. E.; Bukauskas, F. F.; Francesconi, A., Actinin-4 Governs Dendritic Spine Dynamics and Promotes Their Remodeling by Metabotropic Glutamate Receptors. The Journal of biological chemistry 2015, 290, (26), 15909-20.

148. Hodges, J. L.; Vilchez, S. M.; Asmussen, H.; Whitmore, L. A.; Horwitz, A. R., alpha-Actinin-2 mediates spine morphology and assembly of the post-synaptic density in hippocampal neurons. PLoS One 2014, 9, (7), e101770.

149. Wyszynski, M.; Kharazia, V.; Shanghvi, R.; Rao, A.; Beggs, A. H.; Craig, A. M.; Weinberg, R.; Sheng, M., Differential regional expression and ultrastructural localization of alpha-actinin-2, a putative NMDA receptor-anchoring protein, in rat brain. J Neurosci 1998, 18, (4), 1383-92.

150. Michailidis, I. E.; Helton, T. D.; Petrou, V. I.; Mirshahi, T.; Ehlers, M. D.; Logothetis, D. E., Phosphatidylinositol-4,5-bisphosphate regulates NMDA receptor activity through alpha-actinin. J Neurosci 2007, 27, (20), 5523-32.

151. Lanzetti, L.; Palamidessi, A.; Areces, L.; Scita, G.; Di Fiore, P. P., Rab5 is a signalling GTPase involved in actin remodelling by receptor tyrosine kinases. Nature 2004, 429, (6989), 309-14.

152. Kim, J. H.; Lee-Kwon, W.; Park, J. B.; Ryu, S. H.; Yun, C. H.; Donowitz, M., Ca(2+)-dependent inhibition of $\mathrm{Na}+\mathrm{H}+$ exchanger 3 (NHE3) requires an NHE3-E3KARP-alpha-actinin-4 complex for oligomerization and endocytosis. The Journal of biological chemistry 2002, 277, (26), 23714-24. 
153. Araki, N.; Hatae, T.; Yamada, T.; Hirohashi, S., Actinin-4 is preferentially involved in circular ruffling and macropinocytosis in mouse macrophages: analysis by fluorescence ratio imaging. J Cell Sci 2000, 113 ( Pt 18), 3329-40.

154. Emlet, D. R.; Moscatello, D. K.; Ludlow, L. B.; Wong, A. J., Subsets of epidermal growth factor receptors during activation and endocytosis. The Journal of biological chemistry 1997, 272, (7), 4079-86.

155. Luthi-Carter, R.; Apostol, B. L.; Dunah, A. W.; DeJohn, M. M.; Farrell, L. A.; Bates, G. P.; Young, A. B.; Standaert, D. G.; Thompson, L. M.; Cha, J. H., Complex alteration of NMDA receptors in transgenic Huntington's disease mouse brain: analysis of mRNA and protein expression, plasma membrane association, interacting proteins, and phosphorylation. Neurobiol Dis 2003, 14, (3), 624-36.

156. Tousley, A.; Iuliano, M.; Weisman, E.; Sapp, E.; Richardson, H.; Vodicka, P.; Alexander, J.; Aronin, N.; DiFiglia, M.; Kegel-Gleason, K. B., Huntingtin associates with the actin cytoskeleton and alpha-actinin isoforms to influence stimulus dependent morphology changes. PLoS One 2019, 14, (2), e0212337.

157. Galloway, P. G.; Perry, G.; Kosik, K. S.; Gambetti, P., Hirano bodies contain tau protein. Brain Res 1987, 403, (2), 337-40.

158. Hirano, A., Hirano bodies and related neuronal inclusions. Neuropathology and applied neurobiology 1994,

159. Garton, F. C.; Seto, J. T.; Quinlan, K. G.; Yang, N.; Houweling, P. J.; North, K. N., alpha-Actinin-3 deficiency alters muscle adaptation in response to denervation and immobilization. Human molecular genetics 2014, 23, (7), 1879-93.

160. Key, J.; Kohli, A.; Barcena, C.; Lopez-Otin, C.; Heidler, J.; Wittig, I.; Auburger, G., Global Proteome of LonP1(+/-) Mouse Embryonal Fibroblasts Reveals Impact on Respiratory Chain, but No Interdependence between Eral1 and Mitoribosomes. Int J Mol Sci 2019, 20, (18).

161. Auburger, G.; Gispert, S.; Torres-Odio, S.; Jendrach, M.; Brehm, N.; Canet-Pons, J.; Key, J.; Sen, N. E., SerThr-PhosphoProteome of Brain from Aged PINK1-KO+A53T-SNCA Mice Reveals pT1928-MAP1B and pS3781-ANK2 Deficits, as Hub between Autophagy and Synapse Changes. Int J Mol Sci 2019, 20, (13).

162. Torres-Odio, S.; Key, J.; Hoepken, H. H.; Canet-Pons, J.; Valek, L.; Roller, B.; Walter, M.; Morales-Gordo, B.; Meierhofer, D.; Harter, P. N.; Mittelbronn, M.; Tegeder, I.; Gispert, S.; Auburger, G., Progression of pathology in PINK1-deficient mouse brain from splicing via ubiquitination, ER stress, and mitophagy changes to neuroinflammation. J Neuroinflammation 2017, 14, (1), 154.

163. Feng, Y.; Gutekunst, C. A.; Eberhart, D. E.; Yi, H.; Warren, S. T.; Hersch, S. M., Fragile X mental retardation protein: nucleocytoplasmic shuttling and association with somatodendritic ribosomes. The Journal of neuroscience : the official journal of the Society for Neuroscience 1997, 17, (5), 1539-47. 